\title{
DEVELOPMENT OF A LABORATORY PROTOCOL FOR THE MICROPROPAGATION OF MONTEREY PINES (PINUS RADIATA), AÑO NUEVO STAND
}

\author{
A Master's Thesis \\ Presented to the Faculty of \\ California Polytechnic State University, San Luis Obispo
}

\author{
In Partial Fulfillment \\ of the Requirements for the Degree \\ Master of Science in Forestry Sciences
}

by

Karen Elizabeth Wells

May 2009 
(C) 2009

Karen Elizabeth Wells

ALL RIGHTS RESERVED 


\title{
COMMITTEE MEMBERSHIP
}

TITLE: Development of a laboratory protocol for the micropropagation of Monterey pines (Pinus radiata), Año Nuevo stand

\author{
AUTHOR: Karen Elizabeth Wells
}

DATE SUBMITTED: $\quad$ May 2009

COMMITTEE CHAIR: $\quad$ Walter R. Mark, Ph.D, Natural Resources Management

COMMITEE MEMBER: Jeffrey C. Wong, Ph.D, Horticulture and Crop Science

COMMITTEE MEMBER: $\quad$ Scott J. Steinmaus, Ph.D, Biological Sciences 


\begin{abstract}
Development of a laboratory protocol for the micropropagation of Monterey pines (Pinus radiata), Año Nuevo stand

Karen Elizabeth Wells
\end{abstract}

Monterey pine (Pinus radiata), a native tree to California and two Mexican islands, is important both ecologically and economically. Outside native stands, Monterey pines are grown for landscaping in California and on plantations around the world. Pitch canker, a disease caused by the fungus Gibberella circinata Nirenberg \& O'Donnell (Fusarium circinatum Nirenberg and O'Donnell) is threatening the survival of Monterey pines. The disease currently affects Monterey pines in many parts of the world including the native stands. No effective chemical or biological control is available but some Monterey pines show resistance to the disease. The purpose of this project was to develop a working protocol for producing genetic clones of the resistant pines through micropropagation. These genetic clones will be used for outplanting in places outside the native stands for ornamental and plantation purposes. This project analyzes the results of ten trials with varied parameters and bases the final protocol on the parameters used in the trial that induces the growth of new shoots.

The final protocol developed in this project describes, step-by-step, the media preparation for the initiation, plant material collection, surface sterilization of plant material, plating in media and initiation of shoots on explants. The protocol calls for collecting shoot tips with hardened buds that have not yet elongated, then washing the shoot tips in sterile water with Tween 20 for 15 minutes. The shoots tips are then surface sterilized in a $50 \%$ bleach solution for 20 minutes. The explants are broken into disks (to minimize damage to the cells) by inserting the tip of a 
scalpel and tilting it slightly. The initiation media shown to induce growth consists of $1 / 2$ strength LePoivre basal salt mixture, $5 \mathrm{mg} / \mathrm{L}$ benzylaminopurine, $3 \%$ sucrose and $0.8 \%$ agar and is adjusted to a pH of 5.7, then autoclaved for 20 minutes. The explants are inserted into solidified media and incubated in a growth chamber programmed for 16 hours of light and 8 hours of dark with temperatures of $27^{\circ} \mathrm{C}$ and $22^{\circ} \mathrm{C}$ and light irradiance of $80 \mu \mathrm{Em}^{-2} \mathrm{~s}^{-1}$. After 1 month the protocol calls for transferring the growing shoots to elongation media with full LP basal salts and transferring every month. When the number of desired shoots has been reached the forthcoming protocol for rooting can be followed. 


\section{ACKNOWLEDGMENTS}

This project would not have been successful without the help and support of several people. Peter Jankay volunteered his time to teach me the basic laboratory techniques used in micropropagation and helped me to trouble shoot when trials failed. Bill Werner supplied plant material for several trials and made suggestions based on his experience with traditional plant propagation. Several researchers in New Zealand communicated electronically by answering many of my questions and recommending articles that might be helpful for my project. These were Kathy Horgan, Jenny Aitken-Christie and Cathy Hargreaves. Jeff Wong, the principle investigator and member of my committee, listened and helped brainstorm when I was completely frustrated when trial after trial failed or became contaminated. Charles Knight, Nancy Reid and the biology department lent me laboratory space, tools and equipment. Walter Mark, my advisor, provided the opportunity and funding for the project and shared his experience in a micropropagation laboratory in New Zealand. Several unnamed people helped me by collecting plant material, sharing their knowledge in the area of plant propagation and offering encouragement when the project was not succeeding. Finally, I would like to acknowledge the trees from which the samples were taken and the branch tips that finally produced growing shoots. For without Monterey pine trees in parks, residential backyards and

golf courses near native Monterey pine stands, the atmosphere on the central coast of California would not be the same. 


\section{TABLE OF CONTENTS}

LIST OF TABLES. IX

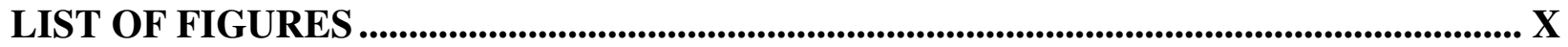

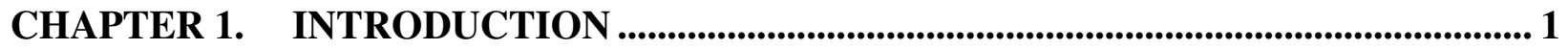

Background Information ...........................................................................................................

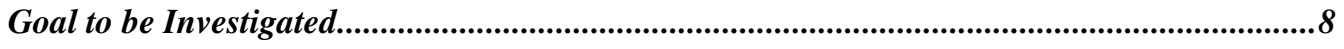

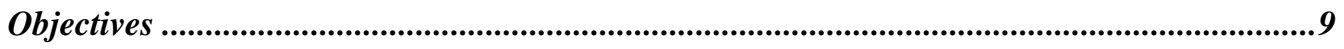

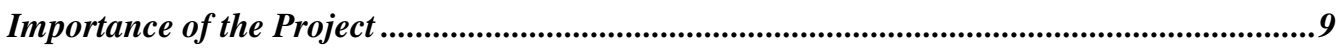

General Approach

CHAPTER 2. LITERATURE REVIEW ................................................................... 11

Importance of radiata pine (Monterey pine) outside their native range ...................................11

Use of micropropagation to produce tree stock and conserve genetics.....................................13

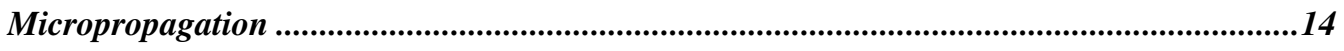

Review of Micropropagation Techniques as applied to Monterey pine ..................................15

Use of compounds and reasons for their use ............................................................................19

Pre-made media ….........................................................................................................................21

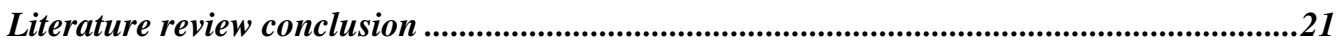

CHAPTER 3. MATERIALS AND METHODS................................................................. 22

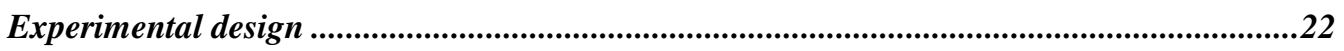

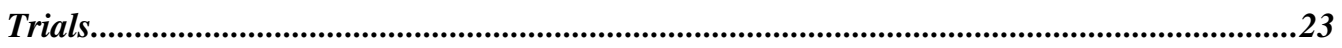

Initiation Stage Preparation Procedures......................................................................................26

Monitoring for growth, contamination and dead tissue ..........................................................28

Determination of the source of contamination ....................................................................28

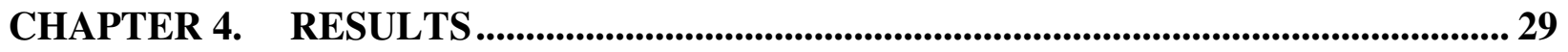

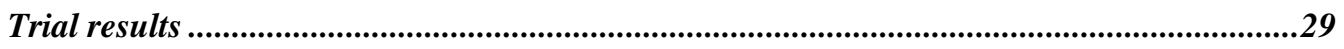


Results of tests to determine the source of contamination.............................................................32

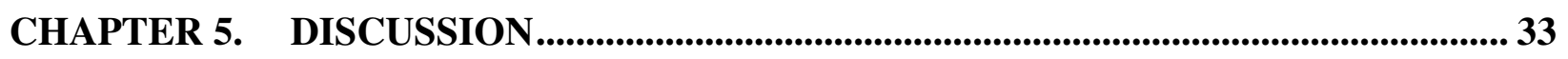

Contamination problems............................................................................................3

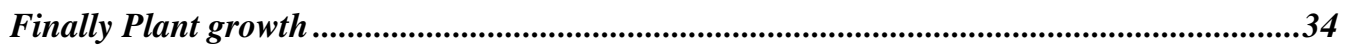

Summary of Critical Materials and Methods.................................................................................36

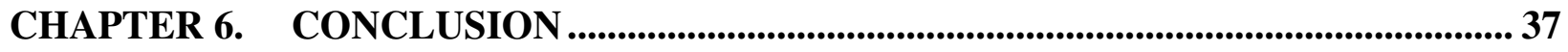

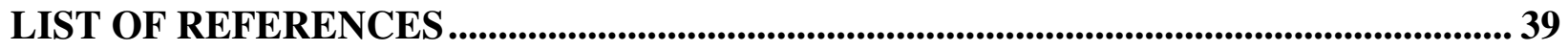

APPENDIX 1. PLANT MATERIAL COLLECTION LOCATIONS .................................. 44

APPENDIX 2. SUMMARY TABLE OF TRIAL PARAMETERS................................. 45

APPENDIX 3. QUOIRIN AND LEPOIVRE BASAL SALT MIXTURE ........................... 46

APPENDIX 4. WRITTEN PROTOCOL ....................................................................................... 48 


\section{LIST OF TABLES}

Table 1. Micropropagation parameters from the literature and unknown parameters................ 22

Table 2. Locations where plant material was collected for each trial.................................... 44

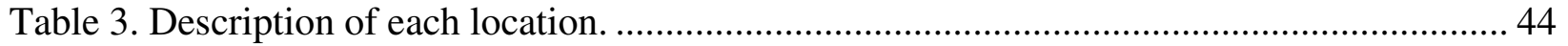

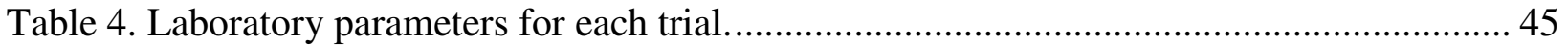

Table 5. Components of Quoirin and Lepoivre basal salt mixture.......................................... 46 


\section{LIST OF FIGURES}

Figure 1. Map of the locations of native Monterey pines in Año Nuevo, Monterey, Cambria, Cedros Island and Guadalupe Island.................................................................. 2

Figure 2. Distribution of Pitch Canker in California as of November 2002 ............................. 4

Figure 3. Geographic locations of Monterey pines shown to be resistant to pitch canker........... 6

Figure 4. Contaminated explants from trial 3 after about 2 weeks...................................... 32

Figure 5. These explants are just starting to grow after about 1 month.................................... 32

Figure 6. Growing shoots on an explant in initiation nutrient media. ..................................... 35

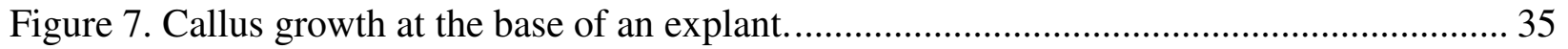




\section{Chapter 1. Introduction}

\section{Background Information}

Pinus radiata D. Don, known as Monterey pine in the United States and radiata pine elsewhere in the world is native to coastal California and two Mexican islands. In California, there are three stands that total 4,500 ha in Año Nuevo, Monterey Peninsula and Cambria. The two islands, Cedros Island and Guadalupe Island are home to 150 ha and 400 trees, respectively (Gordon et al. 2001, Figure 1). In addition to its importance as a native species in California, Monterey pines are valuable ornamental trees and widely used in parks and golf courses.

Monterey pine grows outside its native range in plantations in New Zealand, Chile, Australia, Spain, South Africa, Argentina, Turkey, Great Britain and Ireland (Gordon 2005, Rogers 2002). These countries harvest the trees for sawn timber and fiber. 


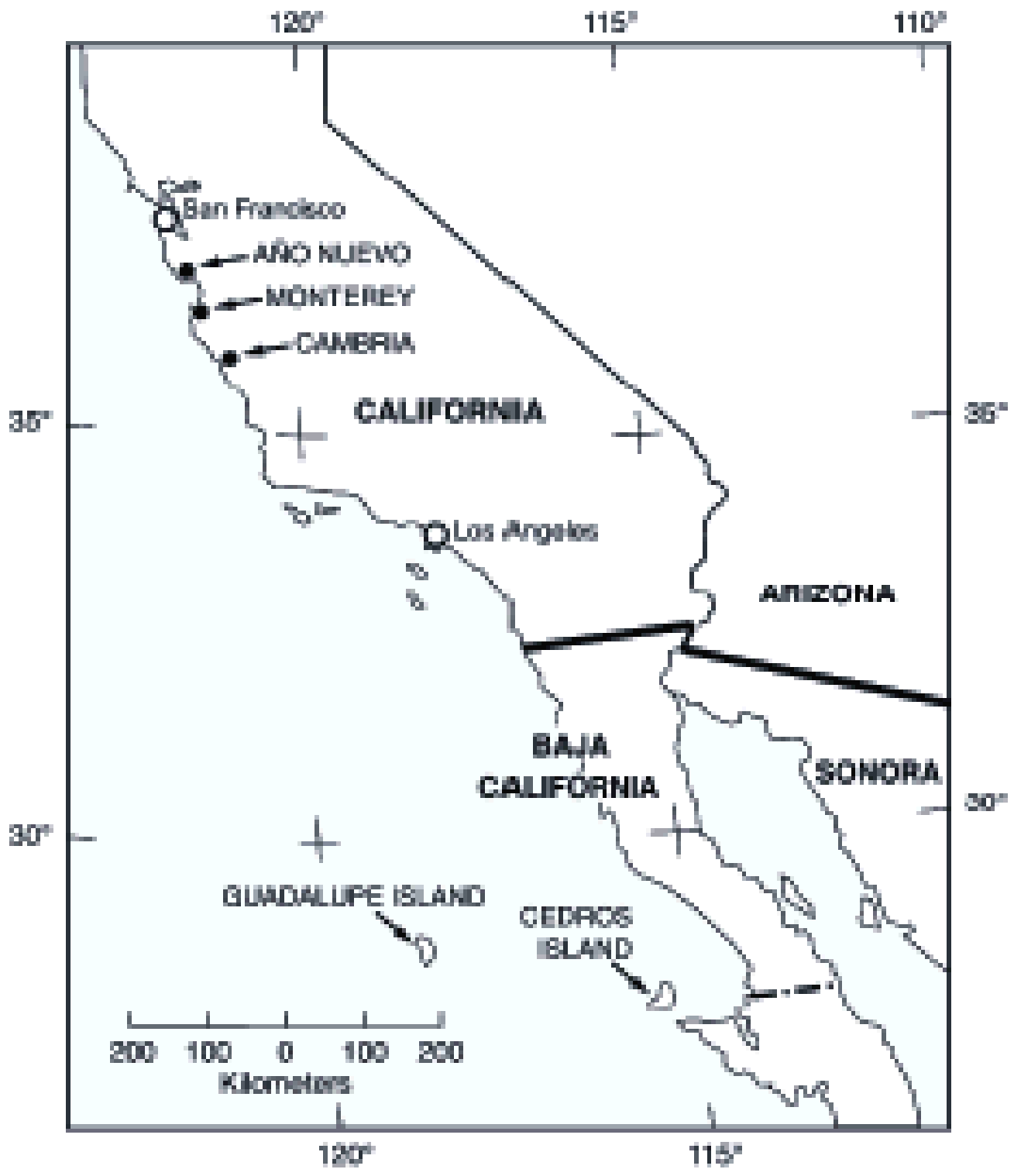

Figure 1. Map of the locations of native Monterey pines in Año Nuevo, Monterey, Cambria, Cedros Island and Guadalupe Island.

(Adapted from Rogers et. al. 2002) 
Monterey pines in California are currently being affected and threatened by a disease called pitch canker. Pitch canker is caused by the fungus Gibberella circinata Nirenberg \& O'Donnell (Fusarium circinatum Nirenberg and O'Donnell). Infections are characterized by resinous cankers in woody parts. Each infection is a separate inoculation event caused by either airborne spores or propagules from feeding insects that infect fresh wounds (Storer et al. 1998). Cankers of oozing pitch develop in the trunk, limbs, cones and roots. Resinous pitch soaks infected areas and surrounding wood. Young trees die from infections that girdle the main stem. Older susceptible trees progressively decline from branch dieback, top kill and bark beetle attack (Owen 1998).

Pitch canker is native to southeastern United States and affects a number of pines including common southern plantation species, slash pine (Pinus elliottii Engelm) and loblolly pine (Pinus taeda L.) (Blakeslee et al. 1998). In 1986, the disease was first discovered in California in two distinct locations, the South San Francisco Bay Area and the Santa Cruz area (McCain et al. 1987, Dwinell 1998, Adams 1997) and Santa Barbara soon after (Adams et al. 1998). Pitch canker was later isolated from all three native Monterey pine stands. In 1992, the pitch canker pathogen was identified in both the Monterey peninsula and the Año Nuevo stands and in 1994 in the Cambria stand (Storer et al. 1994). Pitch canker has since been found at epidemic levels in multiple counties in California (Figure 2). The global distribution of pitch canker includes the United States, Haiti, Japan, Mexico, Spain, South Africa (Dwinell 1998), South Korea and Chile (T. Gordon, personal communication, 2005). 


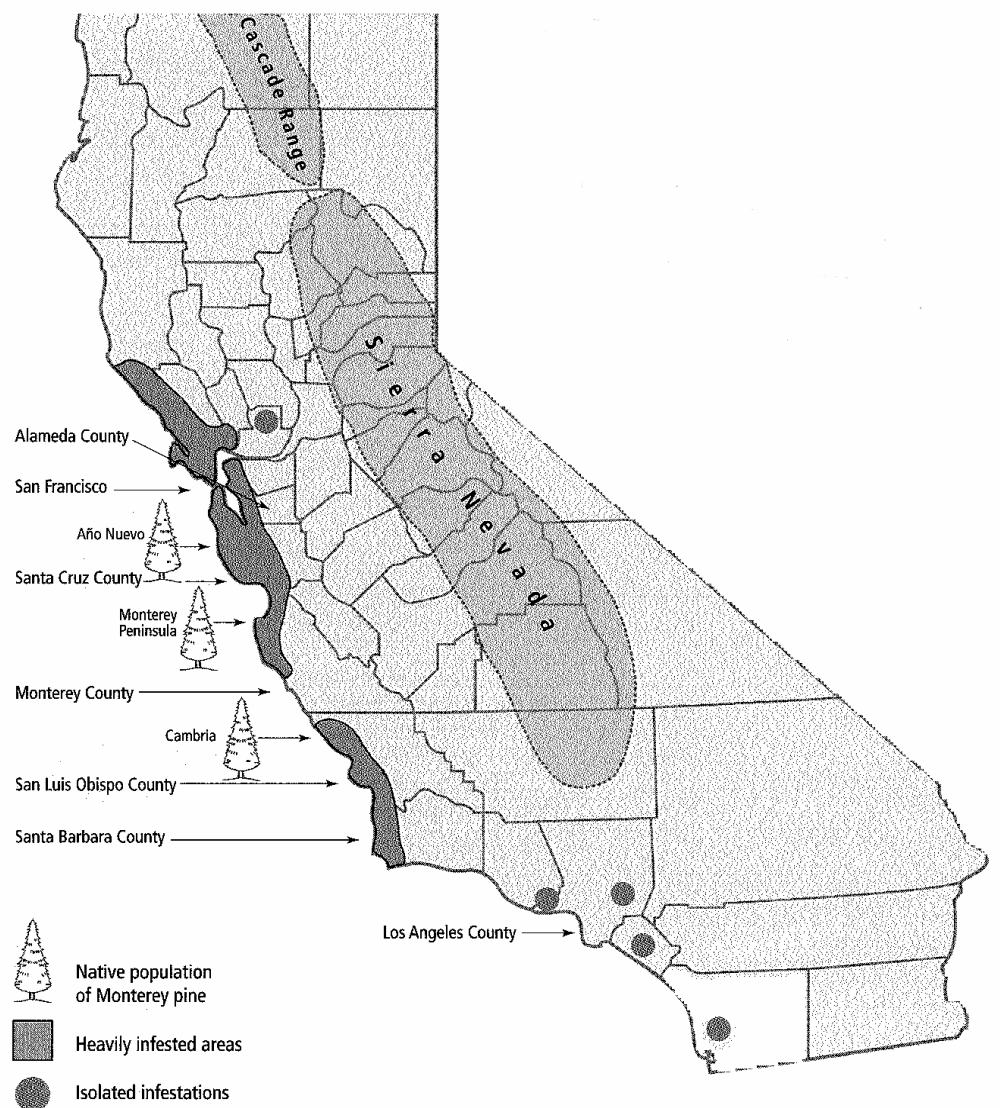

Figure 2. Distribution of Pitch Canker in California as of November 2002. (Adapted from Aegerter et al. 2003.) 
Pitch canker has the potential to cause severe reductions in the genetic diversity of Monterey pine and impact the integrity of native stands (Dallara et al. 1995). There are no effective chemical or biological agent controls available for pitch canker (Dallara et al. 1995) but some Monterey pines are not affected even in pitch canker infested areas. When 100 trees in the Ano Nuevo Stand were inoculated with G. circinata, 13 showed resistance to pitch canker (Figure 3). These trees are located on private land in six different ownerships; Swanton Pacific Ranch, Big Creek Ranch, Coastways Ranch, Gianoni Ranch, Rancho Del Oso and Cal Trans right-of-ways. These trees could potentially be used to produce a clonal resistant population for landscaping and plantation purposes (Mark, W., personal communication, 2005). 


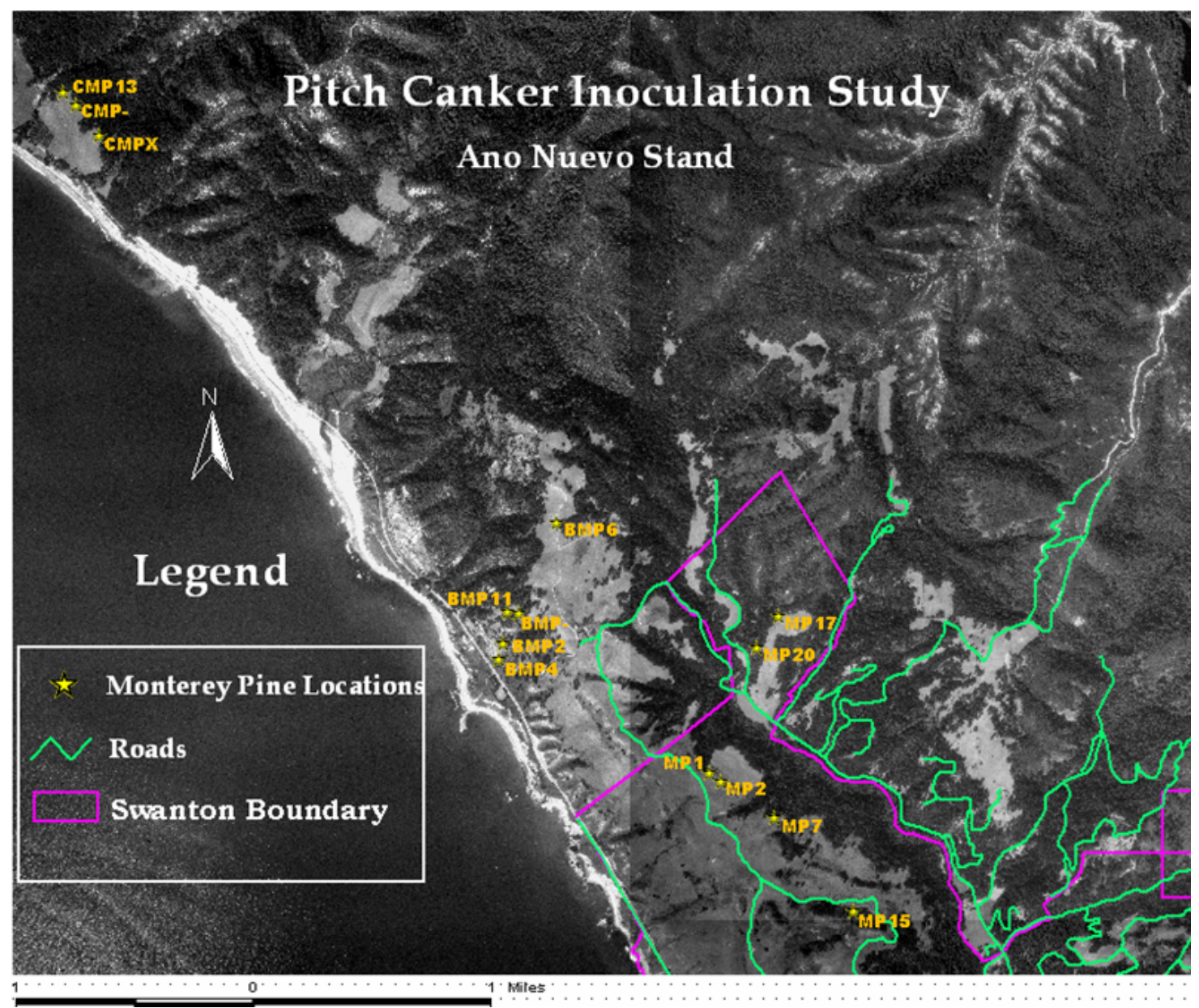

Figure 3. Geographic locations of Monterey pines shown to be resistant to pitch canker. (Map supplied by David Yun, GIS specialist.) 
There are a few methods of vegetative propagation including grafting, rooting of cuttings (macropropagation or traditional propagation) and micropropagation. All three of these methods produce clones of the parent plant but the method chosen depends on the objective of the propagation project.

Grafting is the process where two different plants are connected and grown as one. An advantage is that two attributes usually not occurring in a single plant can be combined. For example, an individual with dwarfing of disease-resistant roots can be grafted to an individual with flavorful fruit. Another advantage is that grafting can induce desired characteristics including dwarfing or cold tolerance. There are a few disadvantages to grafting. This method is limited to dicots and gymnosperms. Grafting can be quite expensive because of the root stock seeds and the labor required. The location where the grafting took place might not seal properly and unsightly shoots might grow below the location.

Rooting from cuttings or macropropagation, is a traditional plant propagation technique that produces new plants from the plant parts of a single parent plant. The process might require hormones depending on the species. Some species root from cuttings naturally. Many different parts of the plant can be used including the roots, stems, leaves or leaf buds. Rooting from cuttings is a relatively simple process that can be performed in home and is also used commonly in nurseries. The advantage to this process is that multiple clones can be produced from one plant. Rooting from cuttings does however require more space than micropropagation and is limited in the number of plants that can be produced from one parent plant.

Micropropagation is a method where meristemetic tissue from stock plant material is rapidly multiplied to produce a large number of progeny plants using in-vitro plant tissue culture methods. The method is used to multiply novel plants, especially those that have been 
genetically modified or desired for their disease resistance. When applied to the pitch canker resistant Monterey pines, resistant stock can be produced for planting in non-native land such as parks, residential areas, golf courses and plantations.

Micropropagation has several advantages in comparison to other methods of plant propagation. Progeny plants are genetic clones which retain all the genetic material and phenotypic characteristics of the donor plant. When sterile techniques are used, micropropagation produces disease-free plants that can be imported without the risk of spreading disease from the location where plant material was collected. Micropropagation has high fecundity and takes less space than traditional vegetative propagation. Thousands of new plants can be produced in the same amount of time that traditional techniques would take to produce only a fraction of this number.

There are a few disadvantages. Micropropagation is very expensive and labor intensive. The progeny produced using micropropagation, are clones of the parent plants and thus would offer as much genetic variability as the number of parent plants used. Micropropagation is not a good way to repopulate a natural forest but is a good means of producing trees for timber production and landscaping purposes.

\section{Goal to be Investigated}

The overall goal of this project was to develop a working protocol for the micropropagation of Monterey pines from buds to trees for outplanting. This protocol would include a detailed explanation of the laboratory techniques, plant material collection recommendations, nutrient media preparation, surface sterilization methods and tools necessary for shoot initiation, elongation, multiplication and rooting. The experimental design is based on previously published micropropagation protocols shown to be effective for Monterey pines 
grown in New Zealand. This thesis covers a portion of the overall project, the micropropagation of Monterey pine from buds to initiation of growth and elongation. The working protocol that resulted was not tested for reliability in this phase of the project. Rather, the working protocol is a work in progress that will be used to complete the overall goal of the project and will be used by researchers currently involved in the project.

\section{Objectives}

The objectives met by this project include:

- Use published micropropagation protocols shown to be effective for Monterey pines grown in New Zealand as a basis for developing a working protocol for performing the initiation and elongation stages for micropropagation of Monterey pines grown in California.

- Experimentation with different aspects not described by the published protocol like surface sterilization methods, media ingredients and preparation and the time of year plant material is collected.

- Development of a written protocol that describes, in detail, the materials, field collection and laboratory methods necessary for micropropagation of Monterey pine.

\section{Importance of the Project}

In California and other countries there is a need for a reliable, rapid method for producing pitch canker resistant, vigorous Monterey pine trees that can be planted in parks, private residences, golf courses and plantations. Restrictions and quarantines prohibit the transport of Monterey pines from known pitch canker affected areas (Hosking and Carson 1998). However, these locations are the main and perhaps best source of pitch canker resistant trees. There are 
many known pitch canker resistant trees in Monterey pine stands in California. The rapid method proposed by this project is micropropagation. Compared to traditional vegetative propagation methods using cuttings, micropropagation produces plants in-vitro in a sterile, disease-free environment from small amounts of plant material. Micropropagation also requires less space, less time and less daily care (Trigiano and Gray 2005). Through micropropagation, multiple disease-free, resistant trees can be produced and transplanted into pitch canker-free locations without the threat of pitch canker introduction. The development of this type of material is the ultimate goal of this project.

\section{General Approach}

Shoot tips with hardened buds that were not elongated were collected from adult and juvenile Monterey pines in various locations of the central coast of California. Excised explants from the shoot tips were put into a nutrient growth initiation medium for shoot initiation and later transferred to elongation medium to promote elongation of shoots. The explants were kept inside a growth chamber, where temperature, photoperiod and light intensity were regulated. Multiple experimental methods and nutrient ingredients were tested until plant tissue grew. The protocol was considered working when the first two stages of micropropagation shoot initiation and elongation produced living growing plant tissue. This "best recipe" and the specific methods used are presented as a written protocol. Further laboratory testing will concentrate on the multiplication and rooting stages of micropropagation of Monterey pines. 


\section{Chapter 2. Literature Review}

This literature review highlights the importance of Monterey pines in native forests and the world, the techniques and compounds used in micropropagation and usefulness of micropropagation to produce Monterey pines and conserve genetics.

\section{Importance of radiata pine (Monterey pine) outside their native range}

Non-renewable resources of the world are becoming depleted and renewable resources are becoming more important economically and environmentally. Monterey pines, known as radiata pines outside the US, are the most widely planted (Storer et al. 1994) and one of the most economically important species outside of its native range (Bonello et al. 2001). The pines are found in plantations all over the world. Since the introduction of radiata pines into cultivation, the total area of commercial plantations has grown to 4 million hectares (Rogers 2002). There are large areas of plantations in New Zealand (1.54 million ha), Chile (1.5 million ha), Australia (745,000ha), Spain (237,400 ha), South Africa (71,840 ha), Argentina (15,000 ha), Turkey (2,800 ha), Great Britain (270 ha) and Ireland (300 ha). Economically and environmentally, radiata pine is valued as a plantation species outside the native range because the species supports local economy, serves internal markets, generates valuable foreign exchange reserves as an export and reduces cutting pressure on native forests (McDonald and Laacke 1990).

Radiata pine is particularly valuable in production forests because of the trees high growth rates, desirable lumber and pulp qualities and versatility of uses. In native settings, pine saplings left free to grow on sites with moderate spacing have been observed to increase in height between 1.2 and $2.4 \mathrm{~m}$ (4 to $8 \mathrm{ft}$ ) per year (Lindsay 1937) and trees at 15 years of age typically reach a d.b.h. of $24 \mathrm{~cm}(9.4 \mathrm{in})$ and $16 \mathrm{~m}(53 \mathrm{ft})$ in height (Larson 1915). Plantations in 
other countries where trees are typically thinned and pruned and sometimes fertilized have growth rates that are much higher. In New Zealand, stands 35 to 40 years of age yield $770 \mathrm{~m}^{3} / \mathrm{ha}$ (11,004 ftªcre) (McDonald and Laacke 1990) and grow 50 m³/ha/yr (715 ft³/acre/yr) (van de Hoef 2003). In Chile, radiata pine stands 20 years of age yield $500 \mathrm{~m}^{3} / \mathrm{ha}\left(7,145 \mathrm{ft}^{3} / \mathrm{acre}\right)$. After being thinned 3 times, the density is about 270 trees per ha (109/acre) and $48 \mathrm{~cm}$ (19 in) in d.b.h (McDonald and Laacke 1990). Radiata pine managed over a 25-35 year rotation, grow an average of $18 \mathrm{~m}^{3} / \mathrm{ha} / \mathrm{yr}$ with more than $30 \mathrm{~m}^{3} / \mathrm{ha} / \mathrm{yr}$ (429 ft³/acre/yr) on good sites (van de Hoef 2003).

A wide variety of products are manufactured including roundwood, lumber, gluelaminated lumber, finger-jointed lumber, and plywood and veneer. These products are used for the following (Forest Research Institute 1988):

- Roundwood

$\circ$ power and telephone transition poles

$\circ$ poles for domestic and industrial building foundations and framework

○ posts for farm division fences

○ landscaping

- Lumber

- clear wood for furniture and decorative use

- structural grades for construction and export

○ lower grades for packaging and formwork

- Glue-laminated lumber

- large structural members for commercial buildings, bridge stringers, and light beams and columns for domestic construction

- Finger jointed lumber

○ engineered, structural and decorative applications, particularly with defects such as knots and resin pockets 
- Plywood and veneer

$\circ$ exterior and interior sheathing and panels

$\circ$ treated lumber frame foundations, flooring, pallets and bins

○ box and web beam construction

\section{Use of micropropagation to produce tree stock and conserve genetics}

As the human population of the world is increasing, many renewable resources, such as forests, are being hit hard by development, fragmentation and disease. Monterey pine native forests are no exception and are in fact highly susceptible and threatened by diseases, including pitch canker (Gordon et al. 2001, McCain et al. 1987). This is critical not only for native forests but also commercial plantations because the native forests are the primary source of genetic diversity necessary for long-term success (Rogers 2002).

There are two different approaches to conserving genetics: in situ and ex situ. Both methods are important for different reasons. In situ conservation refers to maintaining existing, native populations within the range of where the species was adapted. The approach works with the entire ecosystem including the other flora, fauna and ecosystem processes. Ex situ conservation refers to the conservation of species outside the natural habitats (Plucknett and Horne 1992). Using this approach, species are commonly conserved in seed banks, clone banks, seed orchards or plantations. While in situ conservation favors genetic changes related to natural selection and regeneration, ex situ enhances the goals of in situ conservation (Rogers 2002).

Micropropagation is not recommended for in situ conservation because the technique can only produce clones of existing genotypes and thus genetic diversity is limited. When applied to ex situ conservation, micropropagation can be useful in conserving and producing clones of existing genotypes. This is especially useful in conserving tree stock for plantations, since 
micropropagation can be used to produce clones of genetically superior and possibly genetically transformed trees (Aitken-Christie and Connett 1992). For example, the genetics of trees that show improved productivity could be conserved though multiple clones.

As applied to reducing the spread of pitch canker outside native forests, many researchers are working within native forests to identify Monterey pines that are resistant to pitch canker through inoculation trials (McCain et al. 1987 and Gorgon 2001). These resistant trees are then multiplied using micropropagation and planted. As an added benefit micropropagation allows the production of disease free trees and thus reduces the likelihood of spreading disease to disease-free areas.

\section{Micropropagation}

Vegetative propagation has long been used for horticultural purposes but has within the last few decades been introduced into forestry for tree production as an alternative to selective breeding from seeds. The advantage to vegetative propagation is that individual plants of known desirable phenotype can be cloned to produce new plants with identical genotypes.

Micropropagation, a specialized form of vegetative propagation, allows for the production of a virtually unlimited number of clones from one parent plant.

The first attempt at micropropagation was reported in 1902 by the botanist Gottlieb Haberlandt. Haberlandt's studies on water hyacinth (Eichhornia crassipes (Mart.) Solms), though not entirely successful, set forth the purposes and potentialities of cell culture in plants. Haberlandt proposed that micropropagation was an elegant way to study plant physiological and morphological problems (Krikorian and Berquam 1969). This proposal spurred research on 
micropropagation in other plants and eventually to the application of plantlet production for out planting.

Micropropagation is now used for a variety of nursery and agricultural applications, including forestry. Serious work on gymnosperms probably began with the success on Sequoia sempervirens_D. Don Endl in 1950 (Ball 1950). Later successes included such conifers as Abies nordmanniana Lk., Zamia integrifolia Ait., Cycas circinalis L., Picea abies L., Pinus gerardiana Wall. and Pseudotsuga menziesii (Mirbel) Franco. Research on these trees led to the experimentation and understanding of many substances important to plant growth and micropropagation including auxins and cytokinins (David 2003). The basic methods for micropropagation of Monterey pine were first reported by researchers in New Zealand (Horgan and Aitken 1981).

\section{Review of Micropropagation Techniques as applied to Monterey pine}

Micropropagation is "an in vitro method of producing clonal offspring identical to the superior stock plant" (Aitken-Christie and Connett 1992). Micropropagation, however, is not that simple. Micropropagation is actually a complex technique involving multiple stages, precise formulations of nutrient media, careful surface sterilization and specific environmental growing conditions. The type and age of plant material, time of year collected and treatment after collection are critical.

Since micropropagation is an in vitro method that uses plant tissues or organs instead of a whole plant, special methods are necessary for making specific nutrients available to the cells. Plants require three different essential sources of nutrition; water, minerals and carbon dioxide. In whole plants, water and minerals are obtained through the root system. Carbon dioxide is 
obtained from the atmosphere and used in photosynthesis to produce usable carbon for energy. Using the carbon and minerals, the meristematic tissue and leaves synthesize vitamins and other plant growth substances. Plants grown in vitro require the same nutrients but are unable to produce them without all of the plant parts. Substances like carbohydrates, vitamins and plant growth substances (cytokinins and auxins) need to be added artificially to the growth media (Ozias-Akins and Vasil 1985).

There are two distinctly different types of micropropagation: embryogenesis and organogenesis. The main difference is that in organogenesis, complete plantlets are formed from pieces of plants by first inducing axillary or adventitious shoots and then inducing rooting. In embryogenesis, plantlets are germinated from somatic embryos (complete with cotyledons and root axes) (Aitken-Christie and Connett 1992). This review will focus on organogenesis, the method used in the experiment discussed in this report.

Organogenesis is broken down into a variable number of stages and the number of stages depends on the author. An overall review of multiple articles and books, there are essentially eight different laboratory stages in the whole process of micropropagation, (a) media preparation for initiation, (b) plant material collection, (c) surface sterilization of plant material, (d) plating in media, (e) initiation of shoots on explants, (f) shoot elongation and shoot multiplication, (g) rooting and (h) acclimation to soil. Most publications describe the four growth stages as (1) initiation, (2) elongation, (3) multiplication and (4) rooting (Aitken-Christie and Thorpe 1984, Horgan and Aitken 1981).

Media preparation. Naturally, the nutrient media used in micropropagation must contain all of these nutritional sources. Media for the initiation stage of micropropagation usually consists of an agar solidifying agent containing sugar, a prepared micro and macro nutrient mix 
and cytokinins. The recommended nutrient media for initiation of Monterey pine includes $0.8 \%$ difco bacto agar, 3\% sucrose, $1 / 2$ strength LePoivre medium (Quirin and LePoivre 1977) and 5mg/L benzylaminopurine (BAP), a plant hormone (Aitken-Christie 1984 and Horgan 1987). Plant material collection. The time of year and age of plant when collected are all critical considerations in collecting plant material. For some plants, the best time of year to collect is during the growing season, whereas for conifers, the best time to collect is during the dormant season (Smith 2000). Plant material for Monterey pines is best collected in the winter when all new primordial are present along the length of the bud (Aitken-Christie, personal communication, 2006). In reference to aging, older trees have been shown to be more difficult to root. Studies show that for trees older than 5-7 years, rooting and early vigor of rooted cuttings may be difficult and unreliable (Menzies and Aimers-Halliday 1997). The likelihood of rooting declines as the physiological age of the tree increases. Trees 1 year old root $90 \%$ of the time, whereas trees 15 years old root only $80 \%$ of the time (Thulin and Faulds 1968). Typically BAP is used to revert adult tissue to juvenile development. Plant hormones are discussed later.

Surface sterilization. Surface sterilization is perhaps the most critical of the 8 stages. Surface contaminants thrive in rich nutrient media and when abundant, can inhibit growth of explants. Hardened buds are typically pre-washed in sterile water and a surfactant (ex. Tween 20) for $15-20$ minutes, and then transferred to a $50 / 50$ bleach/water (6\% bleach active ingredient) solution for another 15-20 minutes. The now surface sterilized hardened buds are then rinsed 3 times in sterile water, the last time being in a sterile laminar flow hood. After the final rinse, the hardened buds are removed using sterile forceps, shaking to remove excess water and transferred to a sterile dry jar (Aitken-Christie 1984, Aitken-Christie and Thorpe 1984 and Hargreaves and Menzies 2007). 
Plating in media. Plating refers to placing of the sterile, trimmed explant in the nutrient media filled petri plates or test tubes. This stage is the least described in the literature beyond the obvious, root side down and shoot side up. The best reference is that of those experienced in micropropagation. Cathy Hargreaves recommends using forceps to push the explants into the agar until the surface is broken (Cathy Hargreaves, personal communication, 2007).

Initiation of growth on explants. Initiation, the first growing stage, is where cells begin to grow and differentiate into tissues. The two types of plant growth that might occur at this stage are shoots and callus tissue. Shoots grow in clumps at the top of the explant and look like tuffs of soft new leaves. Each shoot can be separated and plated to amplify the number of new trees originating from a single bud. Callus is an undifferentiated form of cell division which appears as a green blob at the base of the explant. Callus growth typically occurs at a place where a plant has been injured and is undesirable because the cells will rarely differentiate into shoots. Shoots and callus tissue might occur separately or on the same explant. Shoot growth is the desired type of growth because shoots are the beginning of a new micropropagated tree and callus tissue rarely differentiates into shoots. Initiation typically takes about 3-4 weeks, before the explants are ready to be re-plated on elongation media (Aitken-Christie 1984)

Shoot elongation and shoot multiplication. Shoot elongation, the second growing stage, uses the same media as in initiation except with full LP and excluding BAP. During this stage in Monterey pines, shoots continue to elongate and after several transfers, typically reach about $1.5-2 \mathrm{~cm}$ in length. At each transfer, clumps of shoots are cut into smaller pieces and the new surface placed in contact with the new nutrient media (Aitken-Christie 1984). The callus that typically forms at the base can be removed by cutting and discarded because this type of tissue rarely differentiates into useful tissue. 
During shoot multiplication, the third growing stage, the numbers of shoots per culture are multiplied by topping the apical shoots and allowing the side shoots to grow. The media used in shoot multiplication is the same as in initiation (Aitken-Christie 1984).

Rooting. The rooting stage is when rooting is initiated using root promoting auxins in water agar. Two auxins are used in micropropagation of Monterey pines, indole-3-butyric acid (IBA, $1 \mathrm{mg} / \mathrm{L}$ ) and $\alpha$-Naphthalene acetic acid (NAA, $0.5 \mathrm{mg} / \mathrm{L}$ ) (Aitken-Christie 1984). IBA is an auxin produced naturally in plants, is more stable than IAA and the preferred hormone for root induction in micropropagation. NAA is used especially to promote callus growth.

Acclimation to soil. Acclimation, the final stage of micropropagation, is where the new rooted plantlets are removed from culture and placed in soil. Because tissue-cultured plants are extremely susceptible to wilting, the humidity must be gradually reduced. During this stage, the roots grow and begin to take up nutrients and water from the soil. According to the protocol for Monterey pines, after 5 days of rooting auxin treatment, the explants are then placed in nonsterile peat/perlite/pumice (50/25/25\%) mixture and kept in a high humidity chamber with mist and aeration (Aitken-Christie 1984).

\section{Use of compounds and reasons for their use}

In an in vitro system such as micropropagation, plantlets are unable to synthesis the essential nutrients needed for normal plant growth and tissue development. Thus, nutrients need to be presented in a usable form in the nutrient media where direct absorption can occur. These nutrients include both inorganic and organic compounds.

The inorganic nutrients are categorized into two major groups: macroelements and microelements. Macroelements include nitrogen, phosphorus, sulfur, potassium, magnesium and 
calcium. Nitrogen is perhaps the most important for growth and development of cultured tissues. This element is usually presented in the form of $\mathrm{NH}_{4}+$ with $\mathrm{NO}_{3}$ - Nitrate is thought to raise the $\mathrm{pH}$ of the medium above 5 and thus promote the availability of nitrogen. Microelements include iron, manganese, boron, zinc, molybdenum, copper, iodine and cobalt. Iron deficiency is known to reduce growth (Ozias-Akins and Vasil 1985). Most of these nutrients are in the LP basal salt mixture (Sigma Chemical Company 1992; Appendix 3).

The organic nutrients include carbohydrates, plant growth regulators and vitamins. The most commonly used carbohydrate is sucrose but the other disaccharide type carbohydrates used are maltose, lactose, cellobiose, melibiose and trehalose. Monosaccharides and trisaccharides might also be used depending on the species. (Ozias-Akins and Vasil 1985). Sucrose is generally used in Monterey pines (Aitken-Christie 1984).

The plant growth regulators or plant hormones are chemicals secreted internally in plants that function in plant growth. The chemicals usually occur in low concentrations and cause processes to occur in target cells. Plant hormones used in micropropagation are cytokinins and auxins. Others not used in micropropagation are gibberellins (GA's), abscisic acid (ABA) and ethylene (Ozias-Akins and Vasil 1985).

Cytokinins are substances in plants that have kinetin-like biological activity and are involved in cytokinesis (Skoog et al. 1965). The substances promote cell division and are involved in cell growth, differentiation and other physiological processes (Taiz and Zeiger 2002). Benzylaminopurine (BAP) is a commonly used cytokinin in micropropagation of Monterey pine (Aitken-Christie 1984 and Horgan 1987). BAP is known for stimulating cell division and reverting mature buds back to juvenile bud development (Zhang et al. 2003). 
Auxins are substances that induce cell elongation in stems, lateral root formation, cell division in callus tissues in the presence of cytokinin and whose biological activity is similar to that of indole-3-acitic acid (IAA). In micropropagation of Monterey pines, the auxins, indole-3butyric acid (IBA) and $\alpha$-Naphthalene acetic acid (NAA) are used to induce rooting (AitkenChristie 1984).

\section{Pre-made media}

Many of the frequently used nutrient media formulations are available pre-made from chemical companies that specialize in micropropagation supplies. The formulations made known by the authors of literature are generally named after the authors. For example, LP medium was described by Quirin and Lepoivre (1977) and MS salts were described by Murashige and Skoog (1962).

\section{Literature review conclusion}

Micropropagation is a complex process with multiple stages and possible complications. The process can be somewhat limiting in that the product is an exact clone of the parent plant. Also, age and time of year are critical, especially for conifers. Despite this, micropropagation enables the micropropagator the ability to know exactly what the product will be. While micropropagation is not recommended for direct application to conservation of native forests, the method can support the health of native forests. Overall, micropropagation is a valuable tool for producing tree stock and conserving genetics of desired characteristics. 


\section{Chapter 3. Materials and Methods}

\section{Experimental design}

The design of this project revolved around the application of a micropropagation protocol developed in New Zealand, to native California Monterey pine populations. Previous scientific articles including Aitken-Christie (1984) and Horgan (1987) describe the New Zealand protocol but exclude some important parameters. A series of trials were conducted in order to determine the excluded parameters. Using the known parameters as a starting point, a trial and error approach was used to determine the rest. Success was based on whether contamination was avoided and growth was induced by the parameters used in the trial. The following is a table of parameters as described in the literature and unknown parameters:

Table 1. Micropropagation parameters from the literature and unknown parameters.

\begin{tabular}{|c|c|c|}
\hline CATEGORY & SPECIFICATIONS & UNKNOWNS \\
\hline \multirow[t]{3}{*}{ Surface Sterilization } & $\begin{array}{l}\text { 20/80 (20\% Bleach) or 50/50 (50\% } \\
\text { bleach) Clorox bleach /water solution }\end{array}$ & $\begin{array}{l}\text { Time, concentration, } \\
\text { vacuum treatment? }\end{array}$ \\
\hline & Ethanol rinse (not in publications) & Yes or no, time \\
\hline & Sterile water rinse & Time, replications \\
\hline \multirow[t]{4}{*}{ Media materials } & LePoivre nutrient medium (LP) & Concentration \\
\hline & 5mg/L Benzylaminopurine (BAP) & \\
\hline & $3 \%$ sucrose & \\
\hline & $0.8 \%$ difco bacto agar & $\begin{array}{l}\text { Sterilization period, does } \\
\text { type matter? }\end{array}$ \\
\hline \multirow[t]{3}{*}{ Environmental controls } & $\begin{array}{l}27^{\circ} \mathrm{C} \text { during light and } 22^{\circ} \mathrm{C} \text { during dark } \\
\text { photoperiod }\end{array}$ & \\
\hline & 16 hour light/ 8 hour dark photoperiod & \\
\hline & $\begin{array}{l}80 \mu \mathrm{Em}^{-2} \mathrm{~s}^{-2} \text { average light intensity from } \\
\text { fluorescent bulbs }\end{array}$ & \\
\hline Plant material & Material to collect & $\begin{array}{l}\text { When to collect, care after } \\
\text { collection, preparation }\end{array}$ \\
\hline
\end{tabular}




\section{Trials}

\section{Trial 1: Premier trial}

This first trial was performed November 21, 2005 using material collected from a residential backyard near the intersection of Davenport Creek Road and Buckley Road in San Luis Obispo, California $\left(35^{\circ} 14^{\prime} 7.82^{\prime \prime N}, 120^{\circ} 38^{\prime} 49.16^{\prime} \mathrm{W}\right)$. Buds were soaked in a $20 \%$ bleach solution for 20 minutes with a two minute vacuum treatment, then $70 \%$ ethanol for one minute. The buds were then rinsed 3 times with micropropagation grade water and placed inside the air flow hood. Media prepared for this trial included LP medium (prepared as suggested by manufacturer), $5 \mathrm{mg} / \mathrm{L}$ BAP, $3 \%$ sucrose and $0.8 \%$ purified agar. The media $\mathrm{pH}$ was adjusted to 5.7 and autoclaved for 30 minutes before solidifying into petri plates. Buds were cross-sectioned into disks, by slicing with a scalpel and plated. Plates were placed inside an environmentally controlled growth chamber, set for $27^{\circ} \mathrm{C}$ during light and $22^{\circ} \mathrm{C}$ during dark photoperiod, 16 hour light/ 8 hour dark photoperiod, and $80 \mu \mathrm{Em}^{-2} \mathrm{~s}^{-2}$ average light intensity from fluorescent bulbs.

\section{Trial 2: Extreme pH trial}

On April 11, 2006 buds collected in Cambria, California were surface sterilized in 20\% bleach solution for 20 minutes with a four minute vacuum treatment, then rinsed with $70 \%$ ethanol for one minute. After rinsing the buds three times with micropropagation grade water, the buds were placed inside the air flow hood. The media prepared for this trial included LP medium (prepared as on container), 5mg/L BAP, 3\% sucrose and $0.8 \%$ purified agar. Two hydrogen ion concentrations of media were made: $\mathrm{pH}$ of 4.0 and 5.7. The media was autoclaved for 30 minutes and solidified in petri plates. Bud disks were plated and placed inside an environmentally controlled growth chamber, set for $27^{\circ} \mathrm{C}$ during light and $22^{\circ} \mathrm{C}$ during dark photoperiod, 16 hour light/ 8 hour dark photoperiod, and $80 \mu \mathrm{Em}^{-2} \mathrm{~s}^{-2}$ average light intensity from fluorescent bulbs..

\section{Trial 3: Repeat of premier trial}

This trial was a repeat of the premier trial except the buds were collected from Swanton Pacific Ranch and was performed on May 9, 2006. Other materials and methods were the same. 


\section{Trial 4: Bleach concentration/vacuum trial}

This trial tested the concentration of bleach and use of the vacuum. Buds collected from Pebble Beach on July 10, 2006, were submitted to three different surface sterilization treatments. Buds in treatments one and two were surface sterilized using a $20 \%$ bleach solution and buds in treatment three were surface sterilized with $50 \%$ bleach solution. A vacuum was used for two minutes for buds in treatment one. The vacuum was not used in treatments two and three. All buds were treated with $70 \%$ ethanol for one minute. The media contained LP medium (prepared as on container), $5 \mathrm{mg} / \mathrm{L} \mathrm{BAP,} 3 \%$ sucrose and $0.8 \%$ purified agar. The $\mathrm{pH}$ was adjusted to 5.7 and autoclaved for 30 minutes. Bud disks were plated and placed inside an environmentally controlled growth chamber, set for $27^{\circ} \mathrm{C}$ during light and $22^{\circ} \mathrm{C}$ during dark photoperiod, 16 hour light/ 8 hour dark photoperiod, and $80 \mu \mathrm{Em}^{-2} \mathrm{~s}^{-2}$ average light intensity from fluorescent bulbs..

\section{Trial 5: Bleach/ ethanol duration trial}

This trial tested the effectiveness of the duration of bleach and ethanol treatments. Buds for this trial were collected from Pebble Beach on July 27, 2006. There were three surface sterilization treatments, all using 50\% bleach solution and 70\% ethanol. Buds in treatment one were surface sterilized for 45 minutes in bleach and three minutes in ethanol. In treatment two, 30 minutes of bleach and two minutes of ethanol were used to surface sterilize buds. Buds in treatment three were surface sterilized for 20 minutes in bleach and one minute in ethanol. There was no vacuum treatment. In all three treatments the media contained all the ingredients listed above, adjusted to a $\mathrm{pH}$ of 5.7 and was autoclaved for 30 minutes. The buds were cut into disks,

plated and placed inside an environmentally controlled growth chamber, set for $27^{\circ} \mathrm{C}$ during light and $22^{\circ} \mathrm{C}$ during dark photoperiod, 16 hour light/ 8 hour dark photoperiod, and $80 \mu \mathrm{Em}^{-2} \mathrm{~s}^{-2}$ average light intensity from fluorescent bulbs..

\section{Trial 6: BAP concentration/ bud tip trial}

This trial tested five different BAP concentrations using the bud tips. Buds collected from Pebble beach on August 22, 2006 were surface sterilized using 50\% bleach solution for 30 minutes with no ethanol. The media contained LP medium (prepared as on container), 3\% sucrose, $0.8 \%$ purified agar and BAP concentrations: $0.5,1.0,5.0,10.0$ and $50.0 \mathrm{mg} / \mathrm{L}$. The $\mathrm{pH}$ was adjusted to 5.7 and autoclaved for 30 minutes. The bud disks were plated and placed inside 
an environmentally controlled growth chamber, set for $27^{\circ} \mathrm{C}$ during light and $22^{\circ} \mathrm{C}$ during dark photoperiod, 16 hour light/ 8 hour dark photoperiod, and $80 \mu \mathrm{Em}^{-2} \mathrm{~s}^{-2}$ average light intensity from fluorescent bulbs..

\section{Trial 7: BAP concentration/ below bud tip trial}

This trial was a repeat of the BAP concentration/ Bud tip trial except the plant material plated was the material just below the bud tip. The plant material was collected from Pebble Beach, CA on September 15, 2006. After surface sterilization the bud tip was removed and the needles were removed from the sides using a scalpel. Two disks were cut and plated from each branch tip. The plates were placed in a growth chamber set for $27^{\circ} \mathrm{C}$ during light and $22^{\circ} \mathrm{C}$ during dark photoperiod, 16 hour light/ 8 hour dark photoperiod, and $80 \mu \mathrm{Em}^{-2} \mathrm{~s}^{-2}$ average light intensity from fluorescent bulbs..

\section{Trial 8: Difco bacto agar/ 20 minute autoclave trial}

Buds for this trial were collected October 16, 2006 from Morro Bay State park. The buds were treated with $50 \%$ bleach solution for 30 minutes. The nutrient medium contained LP medium (prepared as on container), 5mg/L BAP, 3\% sucrose and 0.8\% Difco Bacto agar. The media was autoclaved for only 20 minutes unlike the previous trials. The buds were cut into disks, plated and placed into an environmentally controlled growth chamber, set for $27^{\circ} \mathrm{C}$ during light and $22^{\circ} \mathrm{C}$ during dark photoperiod, 16 hour light/ 8 hour dark photoperiod, and $80 \mu \mathrm{Em}^{-2} \mathrm{~s}^{-2}$ average light intensity from fluorescent bulbs.

\section{Trial 9: Repeat of difco bacto agar/ 20 minute autoclave trial}

The buds for this trial were collected by Nate Smith from Swanton Pacific Ranch on October 22, 2006. All other methods and materials were the same as in Difco Bacto agar/ 20 minute autoclave.

\section{Trial 10: New Zealand method trial}

This trial was based on the methodology used for the micropropagation of Monterey pines in New Zealand. There were a few differences in comparison to the previous trials. The buds where collected by Wally Mark and Nate Smith from Swanton Pacific Ranch on December 
4, 2006. The buds where pretreated with soap and water for a few minutes. Then, the needles were pulled from the stem and surface sterilized in 50\% bleach for 15 minutes. (Tween 20 was accidentally omitted.) Two formulations of nutrient media were prepared: $1 / 2$ strength LP and full strength LP. The media contained $5 \mathrm{mg} / \mathrm{L}$ BAP, $5 \%$ sucrose and $0.8 \%$ difco bacto agar was adjusted to pH 5.7 and autoclaved for only 15 minutes. Buds were prepared differently. The bud tip scales were removed so the new growing tissue could grow out unobstructed. Instead of cutting the buds, the buds were broken into disks by inserting the scalpel into the side of the bud crossways and hinged towards the tip. This method is preferred because the break occurs in a place that does less damage to the growing tissue. Then the disks were plated and placed into an environmentally controlled growth chamber, set for $27^{\circ} \mathrm{C}$ during light and $22^{\circ} \mathrm{C}$ during dark photoperiod, 16 hour light/ 8 hour dark photoperiod, and $80 \mu \mathrm{Em}^{-2} \mathrm{~s}^{-2}$ average light intensity from fluorescent bulbs.

\section{Initiation Stage Preparation Procedures}

\section{Media and Supply Preparation}

All water in media preparation was micropropagation grade. The culture medium contained 3.6g/L LePoivre basal salt mixture medium (LP medium; Quoirin and Lepoivre 1977) prepared according to the instructions (Appendix 3), 3\% sucrose, 5mg/L BAP and $0.8 \%$ agar. The BAP was prepared in a stock solution containing $1 \mathrm{mg} / \mathrm{mL}$, using $1 \mathrm{M} \mathrm{NaOH}$ to dissolve. The $\mathrm{pH}$ was adjusted to 5.7 prior to adding agar and then autoclaved. For this $\mathrm{pH}$ adjustment, $\mathrm{NaOH}$ or $\mathrm{HCl}$ was added. Other supplies prepared by autoclaving for surface sterilization and plating included jars of water for rinsing and surface sterilization, scalpel blades, scalpel handles, forceps and watch glasses lined with absorbent filter paper. These supplies were typically autoclaved for 30-45 minutes.

After autoclaving, the media was allowed to cool slightly and then poured into petri plates inside the laminar flow hood. The plates were allowed to cool completely and solidify. The cooled plates were stored in the refrigerator.

\section{Field methods for Collecting Plant Material}

Plant material was collected from trees and hedge stock in different locations. A complete list describing these locations can be found in Appendix 1. Upon collection, the 
healthiest trees were selected. For large trees, branch tips near the base of the crown were sampled and for smaller trees, branch tips near the top were sampled (excluding the apical leader). Branch tips from hedge stock were selected from trees showing previous success in macropropagation and according to size. Branch tips containing buds that had not yet elongated were selected. The largest buds were assumed to be the best for micropropagation.

Each branch tip was pruned 8-10 centimeters below the base of the bud. Buds were stored in open plastic zip lock bags over ice. The duration of storage was dependent on the location of the collection site. Buds were typically stored and plated within 24 hours. Buds from the residential backyard and Morro Bay State Park were plated the same day.

\section{Explant Preparation and Surface Sterilization}

To prepare, the plant cuttings were trimmed to a few centimeters length below the base of the bud. In the first 9 trials, all the needles were cut off at the base. In the last trial, the needles were pulled from the stems. The extra stretch of branch was left in tact as to give the buds a buffer by which the bleach could penetrate without harming the final bud to be plated.

A $20 \%$ or $50 \%$ bleach solution was prepared using the autoclaved jars and 2-3 drops of Tween 20. The length of time for the bleach treatment and whether the buds were treated to a vacuum depended on the trial. If a vacuum was used, treatments lasted two minutes and buds were swirled mid-treatment to completely expose surfaces to bleach. Jars were swirled every few minutes during the remaining time. After the bleach was poured off, buds were treated with $70 \%$ ethanol if required by the trial. Buds were then rinsed with sterile water twice outside the

hood and once inside. After the final rinse, the buds were placed inside a sterile watch glass with filter paper to absorb excess water.

\section{Laminar Flow Hood Preparation and Practices}

The laminar flow hood and all materials were sterilized using 70\% ethanol. Following surface sterilization of the hood surfaces, the hood was allowed to run for several minutes to completely exchange the air in the hood. All procedures with buds were preformed in the center of the hood to prevent obstruction between the materials and the filter in the back, and to keep materials from the front of the hood, where contamination from air-born materials could occur. 
Before contact between tools and plant material, each tool was dipped in alcohol and flamed in an alcohol lamp flame. Plant material that contacted the bottom of the hood was discarded.

\section{Explant Plating}

Sterilized buds were removed one by one from watch glasses using flame sterilized forceps and cut or broken to size using a flame sterilized scalpel. The tips were usually cut or broken off to create a $5 \mathrm{~mm}$ disk. Each explant was placed root side down onto the agar media. Each plate was then wrapped with parafilm to seal the edges. The plates were then placed into an environmentally controlled growth chamber, set for $27^{\circ} \mathrm{C}$ during light and $22^{\circ} \mathrm{C}$ during dark

photoperiod, 16 hour light/ 8 hour dark photoperiod, and $80 \mu \mathrm{Em}^{-2} \mathrm{~s}^{-2}$ average light intensity from fluorescent bulbs.

\section{Monitoring for growth, contamination and dead tissue}

The explants were monitored for growth several times a week. Those showing signs of fungal or bacterial growth were considered contaminated and were discarded when signs appeared. Clean explants were removed from petri plates containing contaminated explants for re-plating in new media. Explants were considered dead if the tissue was no longer green or were contaminated. Explants that remained green were considered alive but not growing. Explants showing growth were considered alive and successful. The trials that produced growing tissues were considered successful and the materials and methods were the basis for the written protocol.

\section{Determination of the source of contamination}

A number of probable sources of contamination were tested to determine whether the contamination was originating from the plating process, tools or explants. Several media filled petri plates were set aside for the tools and flow hood to be tested. Both the scalpel and the manipulation forceps were sterilized by flame and then run through the media. Both tools were then put into contact with clean blotting paper or the surface of the hood before running through the media. One plate was left open in the back of the flow hood while the fan was running for approximately 30 minutes. These plates were then placed in the growth chamber with the other explants. 


\section{Chapter 4. Results}

Of the ten trials preformed in this study, two trials were successful in inducing uncontaminated growth of Monterey pine bud cultures (Figure 5). These were trial 9 (Repeat of difco bacto agar/ 20 minute autoclave trial) and trial 10 (New Zealand method trial). Contamination was observed in all trials but was more prevalent in the first 5 trials and trial 7 (BAP concentration/ Below Bud Tip trial, Figure 4). Trial 6 (BAP concentration/Bud Tip trial) and 8 (Difco Bacto Agar/ 20 Minute Autoclave trial) were unsuccessful in terms of inducing plant tissue growth but the explant cells remained alive. The live tissue was exhibited by the green plant tissue. In this section, results are reported for each trial in terms of observed contamination, living non-growing green plant material, plant growth (callus and shoot) and problems related to methods and materials.

\section{Trial results}

\section{Trial 1: Premier trial}

The premier trial was unsuccessful in inducing growth of the explants but the trial was instrumental in testing out and understanding the techniques used in micropropagation. Of the 4 plates only one of the explants was contaminated. The sterile techniques were thought to have been adequate in removing any potential contaminants. The equipment, including water purifier, laminar flow hood and autoclave worked properly. The unsuccessful growth was thought to be attributed to the $\mathrm{pH}$ of the media or other unknown parameter or parameters.

\section{Trial 2: Extreme pH trial}

In this trial, the media prepared with a $\mathrm{pH}$ of 4.0 failed to solidify completely. Properly solidified media usually remains pliable and holds explants when the plates are tilted. The media adjusted to a $\mathrm{pH}$ of 4.0 was watery and allowed the explants to slide back and forth when the plates were tilted. This is not an uncommon problem with agar media at low $\mathrm{pH}$ levels. Given that the agar should solidify enough to hold the explants in place, further trials used a $\mathrm{pH}$ of 5.7.

There was obviously something else wrong in this trial because the explants still failed to grow. Micropropagation is known to be difficult and often the same techniques might be successful one day and not the next. Genetics play a role and thus future trials used different sources of plant material as well as different methods. 


\section{Trial 3: Repeat of Premier trial}

Beginning with this trial, contamination began to be an issue and the explants still did not to grow. There were no known differences in materials and methods from the original premier trial except that the plant material came from Swanton Pacific Ranch instead of a San Luis Obispo residential backyard. The plant material was thought to not be the problem contributing to contamination. Instead the surface sterilization methods were suspect.

\section{Trial 4: Bleach concentration/vacuum trial}

This trial was again unsuccessful in inducing growth and the increased bleach concentration provided no increased protection against contamination. The low concentrations

of bleach and vacuum treatment were suspected to be killing the explants. None of the literature suggested a vacuum treatment for Monterey pine but the treatment had been shown to be successful in angiosperms. The vacuum treatment was suspected to be disturbing the cells. While a vacuum does improve the ability for bleach to penetrate surface irregularities, to sterilize, it might also be disabling the cells from multiplying.

\section{Trial 5: Bleach/ Ethanol duration trial}

In this trial, the explants treated for 30 and 45 minutes with bleach seemed to be the least contaminated. Uncontaminated explants remained green but did not grow. Contaminated explants were discarded. A 30 minute treatment with bleach was used for all further trials. Ethanol was excluded because it was suspected that the ethanol might be inhibiting the explants from growing.

\section{Trial 6: BAP concentration/ Bud Tip trial}

The exclusion of ethanol had no negative effect on the surface sterilization and the explants still remained green. Explants did not grow in any of the BAP concentrations. 


\section{Trial 7: BAP concentration/ Below Bud Tip trial}

The only difference in this trial was that a different part of the bud was used. This resulted again in no growth but still the explants remained green. Since all the previous studies used a concentration of $5 \mathrm{mg} / \mathrm{L}$, further trials were all conducted with a concentration of $5 \mathrm{mg} / \mathrm{L}$.

\section{Trial 8: Difco Bacto Agar/ 20 Minute Autoclave trial}

An important detail was finally tested in this trial, the amount of time the media was autoclaved. The package of BAP had no indication about how long a preparation should be autoclaved, nor did the protocols in other studies. Literature review on this topic revealed that the media should be autoclaved for no more than 20 minutes because the hormone is not stable beyond 20 minutes at temperatures above $100^{\circ} \mathrm{C}$ (Smith 2000). While none of the explants grew in this trial even after autoclaving for only 20 minutes, it was suspected that something else was to blame. Further trials used the same protocol but plant material was collected from a different location and at a later time of the year.

\section{Trial 9: Repeat of Difco Bacto Agar/20 Minute Autoclave trial}

Finally, there was success in this trial. After 4 weeks, 8 of 10 explants were uncontaminated and showed growth. All 8 showed callus growth and 2 of these showed growth of shoots. The difference in this trial from the difco bacto agar/20 minute autoclave trial was that the plant material was collected at a time of year when the buds were dormant.

\section{Trial 10: New Zealand method trial}

This trial was also successful. Of the 12 plates started, 9 had growth of shoots, 2 were contaminated and 1 had no shoot growth but produced callus growth at the base. Since shoot growth is what is desired, the materials and methods used in this trial will be the basis for the written protocol. After transfer to new media, some explants were lost to callus and contamination. Shoots were split off the eight remaining and transfer to $1 / 2$ concentration BAP to try to initiate roots. Six of these were successful in culture for another month. At this time the cultures were terminated, since this was all that was needed to show the techniques work. 


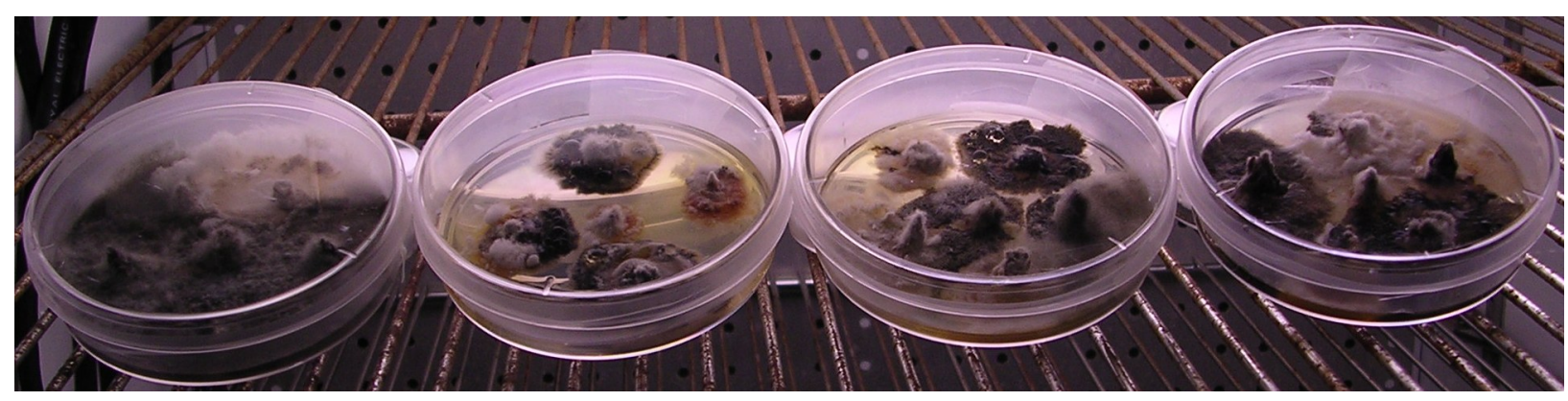

Figure 4. Contaminated explants from trial 3 after about 2 weeks.
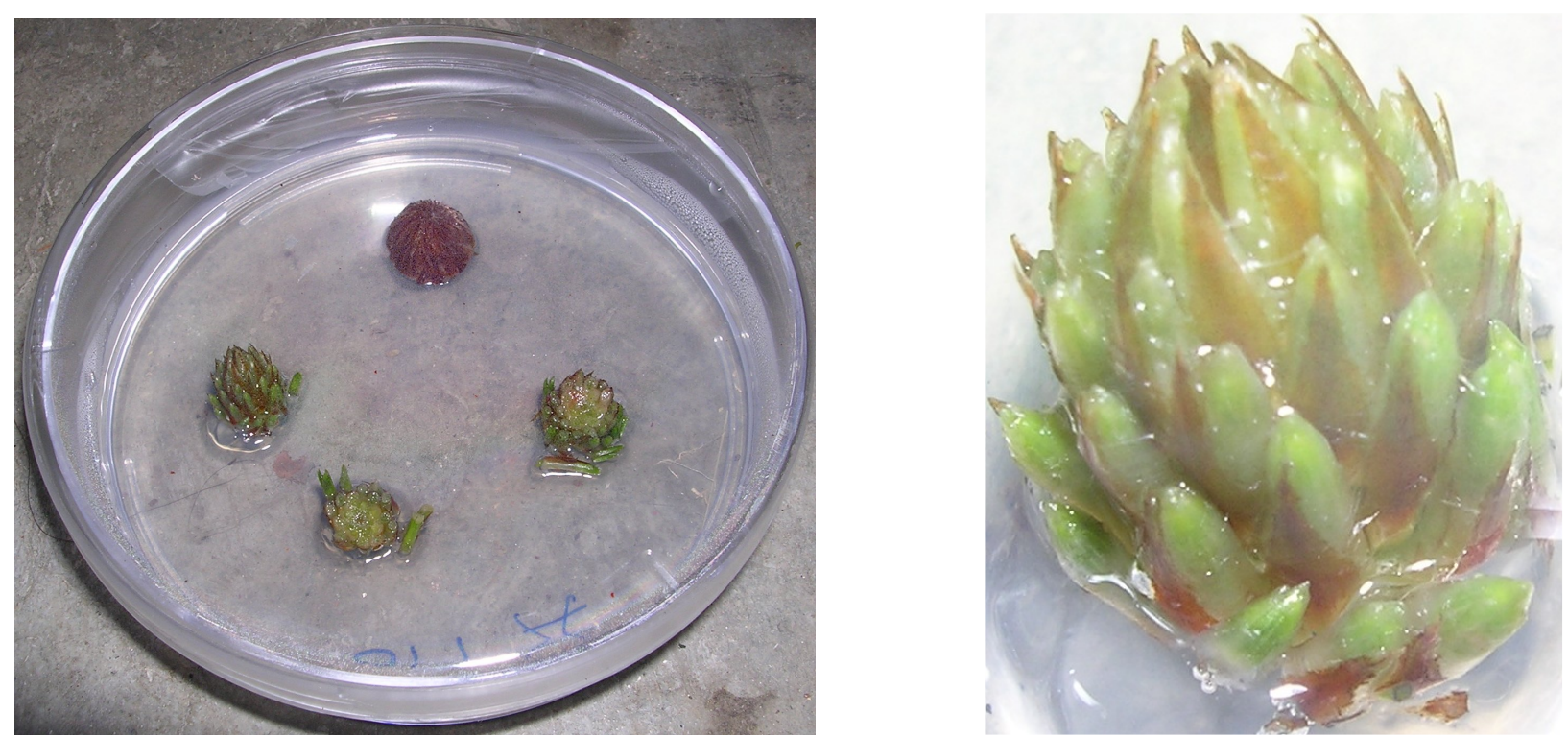

Figure 5. These explants are just starting to grow after about 1 month.

\section{Results of tests to determine the source of contamination}

The tests for determining the source of contamination were visually examined. The only test having visible fungal growth was the open plate. The growth was about $0.5 \mathrm{~cm}$ in circumference after several weeks. 


\section{Chapter 5. Discussion}

After ten trials were performed with varied parameters, a working protocol was determined which resulted in successful growth of Monterey pine from buds using micropropagation. The unknown parameters were determined by trial and error. This final protocol was consistent with previous studies. The complete protocol can be found in Appendix 4. In this discussion section, an analytical approach was taken to discuss the results and what parameters, previously unknown, seemed to be critical for growth of the explants.

\section{Contamination problems}

In the earlier trials, fungal and bacterial contaminations probably contributed to the inhibition of plant growth. Determining exactly how contamination might have gotten introduced into the micropropagation system is difficult. Fortunately, the non-organic materials, such as tools, containers and rinse water can be completely sterilized using an autoclave and thus ruling them as a probable source of contamination. Contamination is more difficult to remove from organic material because there is a risk of killing the cells or causing irreversible chemical changes in hormones from the treatment. The prevention of contamination requires that enough growth inhibiting agents be applied to kill the contaminants without killing the explant.

In this study, the delicate organic materials include plant cuttings and the BAP hormone in the nutrient media. There was something incredibly wrong with the methods used in the first 5 trials and trial 7 (BAP concentration/Below Bud Tip trial) because the explants either became contaminated within a few days or died. One of the differences between the first five trials and the later trials was that ethanol was used in the surface sterilization of the former. Does ethanol kill gymnosperm plant tissue? This study does not answer this question nor rule out the possibility. In later trials, ethanol was shown to be unnecessary for preventing contamination and was thus not included in the final protocol.

In trials 6 (BAP concentration/ Bud Tip trial) and 8 (Difco Bacto Agar/ 20 Minute Autoclave trial), where ethanol was excluded, some explants were uncontaminated and living, as exhibited by green tissue. These living explants failed to grow but just being able to keep the tissue alive suggested that the surface sterilization methods were at least killing the contaminants and not killing the plant tissue. The complete contamination resulting in trial 7 (BAP 
concentration/Below Bud Tip trial), was probably a function of increased handling of the surface sterilized explants in order to isolate the material below the bud tip.

\section{Finally Plant growth}

The only trials successful in producing growth were trials 9 (Difco Bacto Agar/ 20 Minute Autoclave) and 10, (New Zealand method). In both trials, shoot (Figure 6, show shoot growth) and callus tissue growth (Figure 7, show shoots) occurred but in different proportions. There was 60\% more shoot growth in trial 10 than in trial 9. Given that shoot growth is the desired type of growth, determining why trial 10 produced more shoot growth is important. Callus tissue growth is the result of injury to a plant cell and functions in covering and sealing the damaged area. Comparison of the method of preparing disks out of buds in each successful trial suggests that cutting buds into disks, the preparation method trial 9 is more damaging than breaking the buds into disks, the preparation method in trial 10. The scalpel probably has a tendency to injure the cells whereas breaking encourages a natural separation between cells. Another difference in the methods between trials 9 and 10 was the physical removal of bud scales from explants. Bud scales cover the buds and probably impede the growth of shoots by obstructing the growth. Thus in the final protocol, the breaking method and removal of bud scales is suggested for preparing buds. 


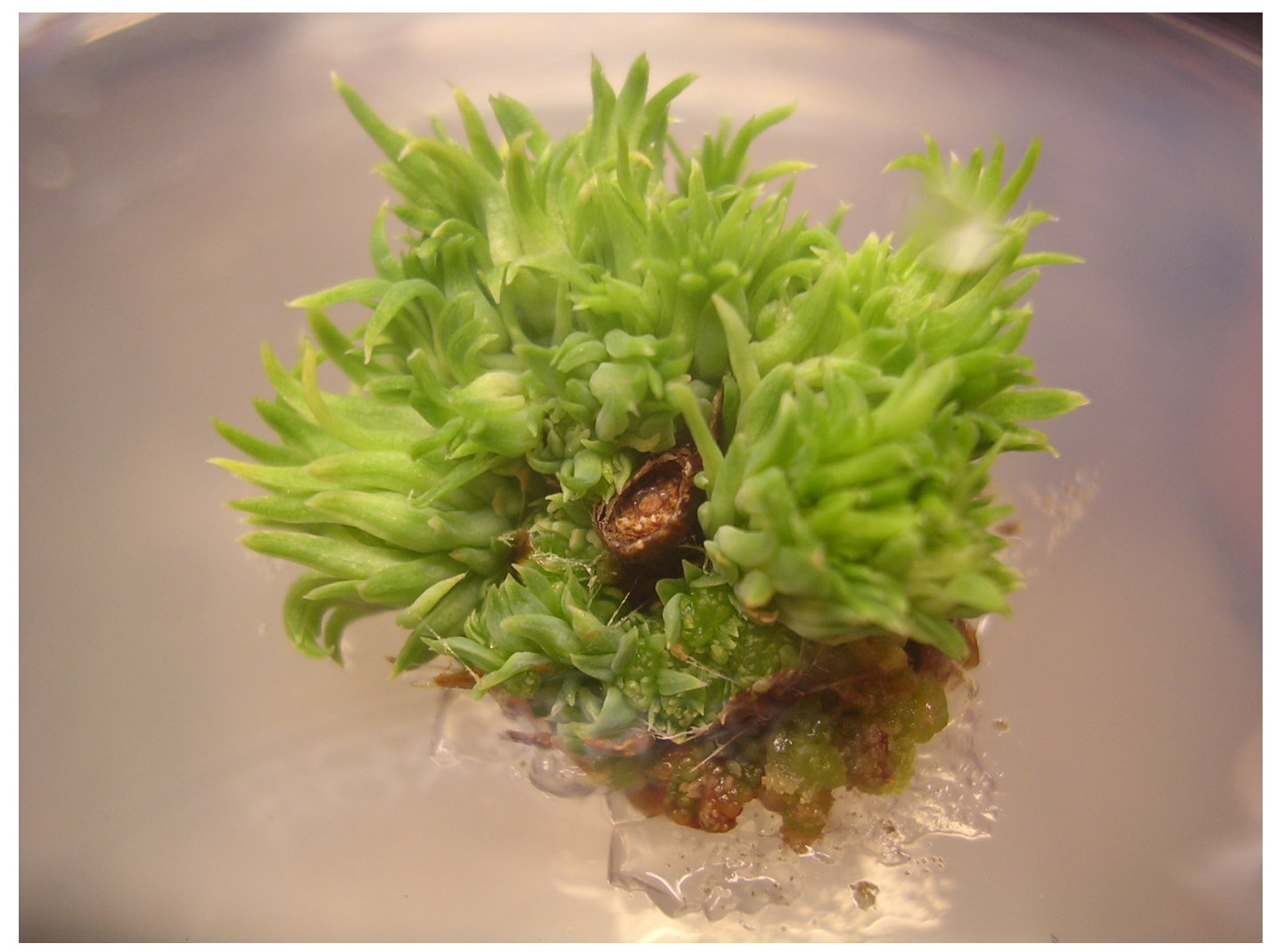

Figure 6. Growing shoots (trial 10) on an explant in initiation nutrient media.

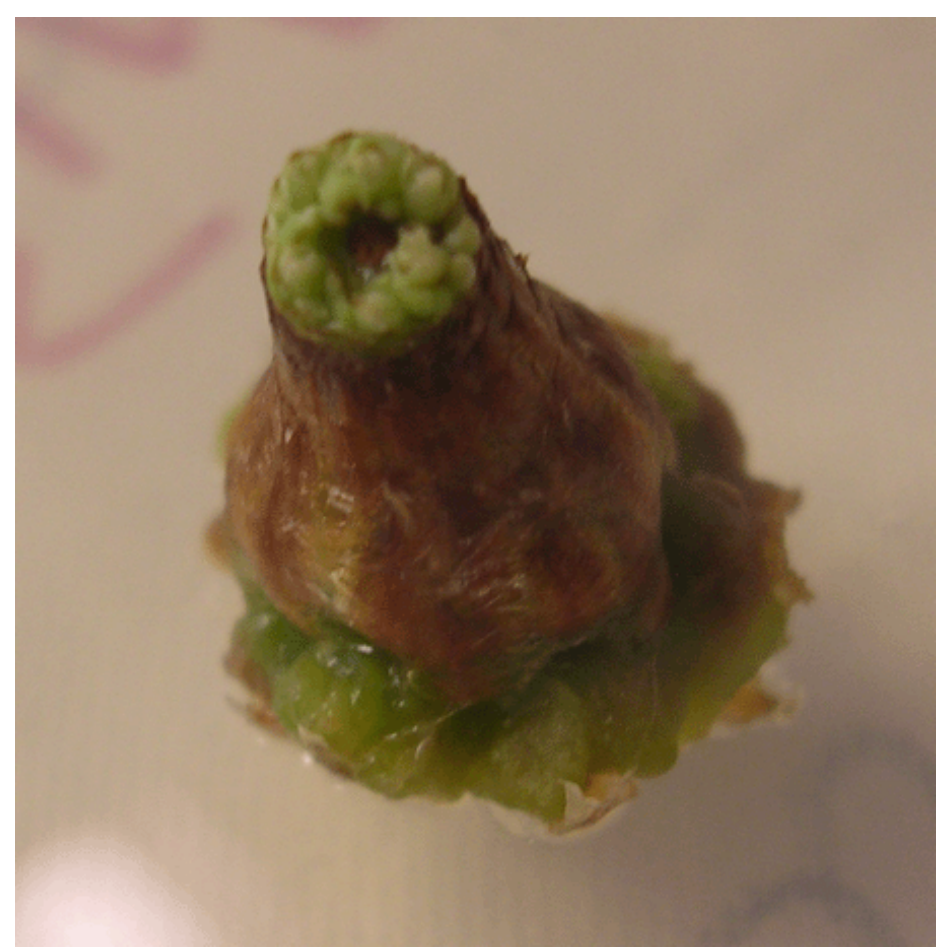

Figure 7. Callus growth at the base of an explant. 
The length of time for nutrient media autoclaving seems to be critical. In the successful trials 9 and 10, the nutrient media was autoclaved for 20 and 15 minutes, respectively. (The media in trial 8 was autoclaved for 20 minutes but was probably unsuccessful for other reasons.) Smith (2000) reported that nutrient media containing BAP is stable for 20 minutes at $100^{\circ} \mathrm{C}$ and that tissue culture media is generally autoclaved at $212^{\circ} \mathrm{C}$ for 15 minutes. Previous studies and the literature that came with the BAP failed to report the maximum length of time for autoclaving. This is surprising considering that stable BAP is a critical nutrient in the media used for the successful micropropagation of Monterey pines.

The source of plant material and time of year were the only differences between unsuccessful trial 8 and successful trial 9. The plant material for trial 8 was collected on October 16 in Morro Bay, which is about 200 miles south of the plant material for trial 9 which was collected at Swanton Pacific ranch on October 22. The 6 day difference between the two collection days might have made a difference at such a critical time of year. (Fall begins in September and winter begins December 20-23 and plant material should be collected during late fall and early winter.) However, genotypic differences might also have played a role. Further research is required to determine whether plant material from Morro Bay can be successfully grown using micropropagation.

\section{Summary of Critical Materials and Methods}

To summarize, the materials and methods found to be critical in this trial are as follows:

$>$ Collection of conifer plant material is best when the buds are dormant. The trials in this study showed successful growth in Monterey pine October through December.

$>$ Surface sterilize using 50\% bleach solution with Tween 20 for 15 minutes. Refrain from using a vacuum or ethanol.

$>$ Prepare media at a $\mathrm{pH}$ of 5.7, BAP of $5 \mathrm{mg} / \mathrm{L}$, using difco bacto agar, and follow the suppliers recommendation for LePoivre nutrient medium

$>$ Autoclave media for no longer than 20 minutes at $212^{\circ} \mathrm{F}$ to avoid irreversible chemical change of the BAP.

$>$ Remove bud scales and break buds into disks before plating rather than cutting 


\section{Chapter 6. Conclusion}

The overall goal of this project was to develop a working protocol for the micropropagation of Monterey pine trees capable of being outplanted. Of the 8 stages of micropropagation, this project describes the first 5 stages. While developing a protocol for growing cultures was a great achievement and the extent of this thesis, the overall goal for the project is not complete. In order to complete that goal, developing a working protocol for the remaining 3 stages is necessary. This project is being continued by Dr. Walter Mark at California Polytechnic University, San Luis Obispo. Upon writing this thesis, Dr. Mark is working on producing root primordia.

Some of the challenges and difficulties encountered in this project would seemingly have been avoided had there been detailed reports of previous studies and better communication with experts who have been developing the protocols over several decades. The experts in micropropagation of Monterey pine are mostly working in New Zealand and in many cases are understandably, reluctant to share details about the process. By the time information was gathered from experts in New Zealand, trial 9 had already proved to be a success. When the new information was applied in trial 10, the methods used in New Zealand did seem to improve the growth, as exhibited by more shoot growth and less callus growth.

Now that the protocol has been completed for the first 5 stages of micropropagation and once a protocol has been developed for the remaining 3 stages, the project can move forward. The next phase would be to test the complete working protocol multiple times to be sure that the protocol is reliable and can be used by others with confidence that it will work. Lastly the reliable protocol will be used to micropropagate individual trees that have been shown to be resistant to pitch canker and test the new trees for resistance. Resistance is important because the purpose of producing clones in this study was to be able to plant the clones in pitch canker infested areas without the trees being significantly affected by the disease. Resistance is a genetic trait and clones will likely retain resistance but this should still be tested.

The development of a protocol for micropropagation is not easy, nor impossible, like some professional people have expressed to the researchers in this project. The real challenge was learning and applying the basic techniques used in micropropagation, applying reported parameters from previous studies, testing unknown parameters and repeating until the project is 
successful. This takes determination, patience and plenty of resources. Fortunately all of these were available and the protocol was successfully developed. 


\section{List of References}

Adams, D. 1997. Monterey pine forest health. Fremontia. 25 (2) 27-30.

Adams, D., S. Frankel and T. Tidwell. 1998. Chronicle of Pitch Canker in California. pp.49-53. In Devey, M., Matheson, C. and Gordon, T. (eds). Current and Potential Impacts of Pitch Canker in Radiata Pine. Proceedings of the IMPACT Monterey Workshop, Monterey, California, 30 Nov to 3 Dec 1998. CSIRO, Australia.

Aegerter, B., T. Gordon, A. Storer and D. Wood. 2003. Pitch Canker: A technical review. Univ. of CA. Agriculture and Natural Resources Publication 21616.

Aitken-Christie, J. 1984. Micropropagation of Pinus radiata. Plant propagators. 30(3) 9-11.

Aitken-Christie, J. and T. Thorpe. 1984. Clonal Propagation: Gymnosperms. p. 82-95. In Vasil, I.K. (eds.) Cell Culture and Somatic Cell Genetics of Plants, vol.1. Academic Press: Orlando, FL.

Aitken-Christie, J. and M. Connett. 1992. Micropropagation of Forest Trees. p. 163-194. In K. Kurata and T. Kozai (eds.) Transplant Production Systems. Kluwer Academic Publishers, Netherlands.

Aitken-Christie, J. personal communication. 2006. Micropropagation scientist. New Zealand. Ball, E. 1950. Differentiation in a callus culture of Sequoia sempervirens. Growth 14:295-325.

Blakeslee G. and D. Rockwood. 1998. Variation in Resistance to Pitch Canker in Slash and Loblolly Pines. pp. 70-75. In Devey, M., Matheson, C. and Gordon, T. (eds). Current and Potential Impacts of Pitch Canker in Radiata Pine. Proceedings of the IMPACT Monterey Workshop, Monterey, California, 30 Nov to 3 Dec 1998. CSIRO, Australia.

Bonello, P., T.R. Gordon, A. Storer. 2001. Systemic induced resistance in Monterey pine. For. Path. 31(2): 99-106.

Dallara, P.L., A.J. Storer, T.R. Gordon and D.L. Wood. 1995. Current status of pitch canker disease in California. Tree Notes. No. 20, July 1995. 
David, A. 2003. In vitro propagation of gymnosperms. In Bonga, J.M. and D.J. Durzan (eds.) Tissue culture in forestry. Springer. Boston.

Dwinell, D. 1998.Global distribution of the pitch canker fungus. pp. 54-57. In Devey, M., Matheson, C. and Gordon, T. (eds). Current and Potential Impacts of Pitch Canker in Radiata Pine. Proceedings of the IMPACT Monterey Workshop, Monterey, California, 30 Nov to 3 Dec 1998. CSIRO, Australia.

Forest Research Institute, New Zealand. 1988. New Zealand radiata pine: A technical appraisal of produce, processes and uses. Ministry of Forestry, Forest Research Institute: Rotorua, New Zealand.

Gordon, T.R., A.J. Storer and D.L. Wood. 2001. The pitch canker epidemic in California. Plant diseases. 85(11): 1128-1139.

Gordon, T.R., personal communication, 2005. Professor in Department of Plant Pathology, University of California, Davis.

Hargreaves, C. personal communication, 2007. Micropropagation scientist. Ensis. New Zealand.

Hargreaves, C. and M. Menzies. 2007. Organogenesis and Cryopreservation of Juvenile Radiata Pine. pgs. 51-65 In Jain, S.M. and H. Haggman (Eds.) Protocols for Micropropagation of Woody Trees and Fruits. Springer Netherlands.

Horgan, K. 1987. Pinus radiata. pgs.128-138 In Bonga, J.M. and D. J. Durzan (eds.) Cell and tissue culture in forestry: Case Histories: Gymnosperms, Angiosperms and Palms. Springer: Boston.

Horgan, K. and J. Aitken. 1981. Reliable plantlet formation from embryos and seedling shoot tips of radiata pine. Physiol. Plant. 53: 170-175. 
Hosking, G.M., Carson, M.D. 1998. Biosecurity strategies for the pitch canker threat to New Zealand's plantation forests. pp. 6-10. In Devey, M., Matheson, C. and Gordon, T. (eds). Current and Potential Impacts of Pitch Canker in Radiata Pine. Proceedings of the IMPACT Monterey Workshop, Monterey, California, 30 Nov to 3 Dec 1998. CSIRO, Australia.

Krikorian, A.D. and D.L. Berguam. 1969. Plant cell and tissue cultures: The role of Haberlandt. Bot. Rev. 35(1) Jan/Mar: 58-67.

Kyte, L. and J. Kleyn. 1996. Plants from test tubes: An introduction to micrpropagation, $3^{\text {rd }}$ edition. Timber press: Portland, Or.

Larsen, Louis T. 1915. Monterey pine. Society of American Foresters Proceedings 10(1):68-74.

Lindsay, A. D. 1937. Report on Monterey pine (Pinus radiata D. Don) in its native habitat. Commonwealth (Australia) Forestry Bureau, Bulletin 10.57 p.

Mark, W., personal communication, 2005. Professor in Department of Natural Resources Management Department, California Polytechnic State University, San Luis Obispo.

McCain, A.H., C.S. Koehler and S.A. Tjosvoid. 1987. Pitch canker threatens California pines. California Agriculture, Nov-Dec. 22-23.

McDonald, P.M. and Laake, R.J. 1990. Silvics. of North America: 1. Conifers; 2. Hardwoods. In Burns, Russell M., and Barbara H. Honkala, tech. coords. (eds.) Agriculture Handbook 654. U.S. Department of Agriculture, Forest Service, Washington, DC. vol.2, 877 p.

Menzies, M.I. and J. Aimers-Halliday. 1997. Propagation options for clonal forestry with Pinus radiata. Proceedings of IUFRO '97 genetics of radiata pine, Rotorua, New Zealand. FRI Bulleton No. 203. 1-4 Dec.

Murashige T and Skoog F. 1962. A revised medium for rapid growth and bioassays with tobacco tissue cultures. Physiol. Plant. 15: 473-97. 
Owen, D., Adams. 1998. Overview of pitch canker in California. pp. 21-23. In Devey, M., Matheson, C. and Gordon, T. (eds). Current and Potential Impacts of Pitch Canker in Radiata Pine. Proceedings of the IMPACT Monterey Workshop, Monterey, California, 30 Nov to 3 Dec 1998. CSIRO, Australia.

Ozias-Akins, P. and I.K. Vasil. 1985. Nutrition of plant tissue cultures. pgs.129-147 In Vasil, I.K. (ed.) Cell culture and Somatic Cell Genetics of Plants. Academic Press. Orlando, FL.

Plucknett, D.L., M.E. Horne, Conservation of genetic resources. Agric. Ecosyst. Environ. Vol. 42, no. 1-2, pp. 75-92. 1992.

Quirin, M. and P. Lepoivre. 1977. Etude de milieux adaptes aux cultures in vitro de prunus. Acta Horticulturae. 78: 437-442.

Rogers, D. 2002. In situ genetic conservation of Monterey pine (Pinus radiata D. Don): Information and recommendations. University of California, Division of Agriculture and Natural Resources, Genetic Resources Conservation Program, Davis, Reports 26, pp. 80.

Rogers, D.L., J.J. Vargas Hernández, A.C. Matheson and J.J. Guarra Santos. 2002. The Mexican island populations of Pinus radiata: An international expedition and ongoing collaboration for genetic conservation. Forest Genetic Resources Bulletin. 30: 23-25.

Sato, A., S.S. deLima, V.R. Affonso, M.A. Esquibel and C.L.S. Lage. 2006. Micropropagation of Chamomilla recutita (L.) Rauschert: A shock treatment model with growth regulators. Scientia Horticulturae 109(2) June 29:160-164

Sigma Chemical Co. Ltd. 1992. Quoirin and Lepoivre basal salt mixture. Product information sheet. Q. 3376.

Skoog F., F.M. Strong and S.O. Miller. 1965. Cytokinins. Science 148: 532-533. 
Smith, R.S. 2000. Plant tissue culture: Techniques and experiments. Academic press: San Diego, CA.

Storer, A., D. Wood and T. Gordon. 1998. Epidemiology of pitch canker disease in California. pp. 30-32. In Devey, M., Matheson, C. and Gordon, T. (eds). Current and Potential Impacts of Pitch Canker in Radiata Pine. Proceedings of the IMPACT Monterey Workshop, Monterey, California, 30 Nov to 3 Dec 1998. CSIRO, Australia.

Storer, A.J., T.R. Gordon, D.L. Wood and P.L. Dallara. 1995. Pitch canker in California. For. Note 110. Sacramento: California Department of Forestry and Fire Protection. 14 p.

Storer, A.J., T.R. Gordon, P.L. and Dallara, D.L. 1994. Pitch canker kills pines, spreads to new species and regions. Cal. Ag. 48(6): 9-13.

Thulin, I. J.; Faulds, T., 1968. N.Z. J. For. 13 (1): 66-77.

Trigiano, R.N., D.J.Gray. 2005. Plant development and biotechnology. CRC Press, Roca Raton, Fl.

van de Hoef, Lyn. 2003. Radiata pine for farm forestry. State of Victoria, Australia Department of Primary Industries, Agriculture notes. Jan 2003. Ag 0810.

Zhang, H., K.J. Horgan, P.H.S. Reynolds and P.E. Jameson. 2003. Cytokinin and bud morphology in Pinus radiata. Physiologia Plantarum 117: 264-269. 


\section{Appendix 1. Plant material collection locations}

Table 2. Locations where plant material was collected for each trial

\begin{tabular}{ccll}
\hline Trial & Date & \multicolumn{1}{c}{ Location collected } & \multicolumn{1}{c}{ Collector(s) } \\
\hline 1 & November 21, 2005 & San Luis Obispo resident backyard & Karen Wells \\
\hline 2 & April 11, 2006 & Strawberry Canyon in Cambria, CA & Karen Wells \\
\hline 3 & May 9, 2006 & Swanton Pacific Ranch & Karen Wells \\
\hline 4 & July 19, 2006 & Pebble Beach & Karen Wells \\
\hline 5 & July 27, 2006 & Pebble Beach & Karen Wells and Kristin Wevill \\
\hline 6 & August 22, 2006 & Pebble Beach & Karen Wells \\
\hline 7 & September 15, 2006 & Pebble Beach & Karen Wells \\
\hline 8 & October 16, 2006 & Morro Bay State Park & Karen Wells \\
\hline 9 & October 22, 2006 & Swanton Pacific Ranch & Nate Smith \\
\hline 10 & December 4, 2006 & Swanton Pacific Ranch & Wally Mark and Nate Smith \\
\hline
\end{tabular}

Table 3. Description of each location.

\begin{tabular}{ll}
\hline \multicolumn{1}{c}{ Location } & \multicolumn{1}{c}{ Description } \\
\hline $\begin{array}{l}\text { San Luis Obispo } \\
\text { residencial backyard }\end{array}$ & $\begin{array}{l}\text { Residential backyard in San Luis Obispo, CA, near the interaction of Davenport } \\
\text { Creek Road and Buckley Road (35'14'7.82"N, 120 38'49.16'W). }\end{array}$ \\
\hline $\begin{array}{l}\text { Strawberry Canyon in } \\
\text { Cambria, CA }\end{array}$ & $\begin{array}{l}\text { A pristine 16-acre woodland nestled between Cambria, CA neighborhoods, } \\
\text { managed by Greenspace, the Cambria land trust }\end{array}$ \\
\hline Swanton Pacific Ranch & $\begin{array}{l}\text { Ano nuevo stand, one of 5 native stands remaining. Part of the Cal Poly Univ } \\
\text { SLO experimental forest. }\end{array}$ \\
\hline \multirow{3}{*}{ Pebble Beach } & $\begin{array}{l}\text { Pebble Beach is a small coastal unincorporated community in Monterey } \\
\text { County, California. The samples were taken from hedge stock which was } \\
\text { produced by macropropagation from several trees at Swanton Pacific Ranch. } \\
\text { The hedges are located behind the green }\end{array}$ \\
\hline Morro Bay State Park & \begin{tabular}{l} 
Forest consisting of planted Monterey pines. Located in Morro Bay, CA. \\
\hline
\end{tabular}
\end{tabular}




\section{Appendix 2. Summary table of trial parameters}

Table 4. Laboratory parameters for each trial.

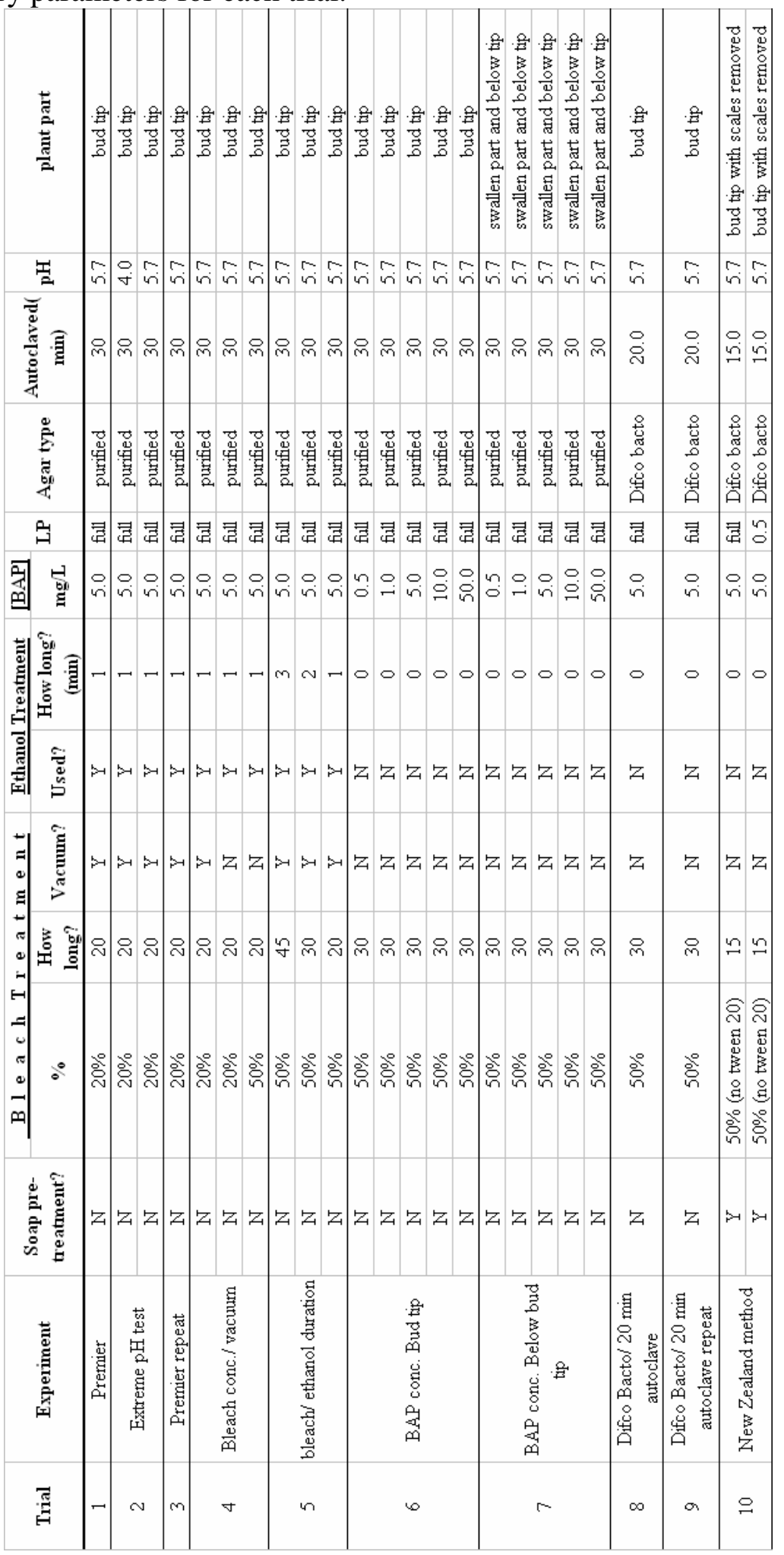




\section{Appendix 3. Quoirin and LePoivre basal salt mixture}

Table 5. Components of Quoirin and LePoivre basal salt mixture.

(Sigma Chemical Co. Ltd. 1992).

\begin{tabular}{|l|c|}
\hline LP media components & Mg/L \\
\hline Ammonium Nitrate & 400.0 \\
\hline Boric Acid & 6.20 \\
\hline Calcium Nitrate (vacuum-dried) & 833.770 \\
\hline Cupric Sulfate Pentahydrate & 0.0250 \\
\hline Cobalt Chloride Hexahydrate & 0.0250 \\
\hline Disodium EDTA Dihydrate & 37.30 \\
\hline Ferrous Sulfate Heptahydrate & 27.80 \\
\hline Magnesium Sulfate Anhydrous & 175.790 \\
\hline Manganese Sulfate & 0.760 \\
\hline Potassium Iodide & 0.080 \\
\hline Potassium Nitrate & 1800.0 \\
\hline Potassium Phosphate Monobasic & 270.0 \\
\hline Sodium Molybdate Dihydrate & 0.250 \\
\hline Zinc Sulfate Heptahydrate & 8.60 \\
\hline
\end{tabular}

Preparation instructions for LP mixture: (Sigma Chemical Co. Ltd. 1992)

Preparing the medium in a concentrated form is not recommended as some salt complexes may precipitate. Supplements may be added prior to sterilization or added aseptically to a sterile medium. Certain supplements (i.e. heat labile) may require filter sterilization and may affect the shelf life of the medium. The basic steps for preparing culture medium are the following:

1. Using a container twice the size of the desired final volume, measure out approximately $90 \%$ of the final required volume of tissue culture grade water (e.g. Sigma Product No. W-3500). Example: $900 \mathrm{ml}$ for a final volume of $1000 \mathrm{ml}$.

2. While stirring the water add the powdered medium.

3 . Rinse the original container with a small volume of tissue culture grade water to remove traces of the powder. Add to the solution in Step 2.

4. Add desired supplements (e.g. vitamins, sucrose, auxin, cytokinin, gelling agent).

5. While stirring, adjust the $\mathrm{pH}$ of the medium (e.g. $5.7+/-0.1$ ) using $\mathrm{KOH}$, $\mathrm{NaOH}$, or $\mathrm{HCl}$.

6. Add additional tissue culture grade water to bring the medium to the final volume. 
7. If a gelling agent is used, heat the solution to approx. $100^{\circ} \mathrm{C}$ while stirring.

8. Dispense the medium into culture vessels before or after autoclaving according to your application. Add heat labile constituents after autoclaving.

9. Sterilize the medium in a validated autoclave at $1 \mathrm{Kg} / \mathrm{cm} 2(15 \mathrm{psi})$. The medium should attain a temperature of $121^{\circ} \mathrm{C}$ for at least $15 \mathrm{~min}$. Refer to the Sigma Plant Cell Culture Catalog for recommended autoclave times for different volumes. 
Appendix 4. Written Protocol

Micropropagation of Monterey pine (Pinus radiata) Laboratory Protocol A work in progress

**This protocol makes 1 liter of media**

A) Materials list

- Equipment

Scale (measures to at least $0.1 \mathrm{mg}$ )

stirring table

$\mathrm{pH}$ meter

Refrigerator

Laminar flow hood

Autoclave

Growth chamber

Alcohol lamp

Nano-water filter

- Supplies

$10 \mathrm{~mL}$ calibrated pipette

2 stir bars

Eye droppers and bulbs

Matches or lighter

Weighing paper

paper bags

Stapler and staples

Foil

Unbleached paper towels

Zip lock plastic bags

Permanente marker

Parafilm

Ice

- Tools

2 scalpel handles

Scalpel blade remover

2 forceps

Sterile scalpel blades

Scissors

Branch clippers

- Plastic and glassware

$50 \mathrm{~mL}$ volumetric flask

Squirt bottle with bent neck

$3500 \mathrm{~mL}$ jars with tops

$1000 \mathrm{~mL}$ graduated cylinder

Spray bottle

$1 \mathrm{~L}$ beaker
Sterilized plastic petri plates $(10 \mathrm{~cm}$ diameter by $1.5 \mathrm{~cm}$ deep)

$150 \mathrm{~mL}$ jar

- media and other liquids

$\mathrm{NaOH}(1 \mathrm{M})$

$\mathrm{HCl}(1 \mathrm{M})$

Micropropagation grade water

Benzylaminopurine (BAP) powder

Quoirin \& Lepoivre basal salt

mixture (LP mix)

De-ionized water

Sucrose

Difco bacto agar

$70 \%$ ethanol

5\% sodium hypochlorite (Clorox

bleach)

$100 \%$ ethanol 
B) Initiation culture medium preparation - Initiation culture medium consists of $1 / 2$ strength LePoivre basal salt mixture (LP mix; Quoirin and Lepoivre 1977) with $5 \mathrm{mg} / \mathrm{L}\left(2.22 \times 10^{-5} \mathrm{M}\right)$ benzylaminopurine (BAP), $3 \%$ sucrose and $0.8 \%$ agar. The methods were adapted from the LP medium preparation guide provided by Sigma Chemical Company and Micropropagation of Pinus radiata (Aitken-Christie 1984).

1) Prepare stock solution of BAP:

a. Into a $50 \mathrm{~mL}$ volumetric flask, add $50 \mathrm{mg}$ BAP powder.

b. Pipet a small amount of $1 \mathrm{M} \mathrm{NaOH}$ into the volumetric flask to help dissolve BAP. Add water forcefully using a spray bottle and swirl. Once powder is mixed well, fill to $50 \mathrm{~mL}$, cover with parafilm and turn upside down several times.

c. Transfer to a $100 \mathrm{~mL}$ storage jar.

2) Into large beaker with stir bar, measure out about $900 \mathrm{~mL}$ of micropropagation grade water (about $90 \%$ of final required media volume).

3) Begin stirring the water. Add $1.8 \mathrm{~g}$ LP mix.

4) Add 30g sucrose.

5) Using a calibrated pipette, add 5mL BAP stock.

6) Adjust $\mathrm{pH}$ of solution to 5.7 using $\mathrm{NaOH}$ (or $\mathrm{HCl}$ ).

7) Add 8g agar. Remove stir bar using another stir bar.

8) Transfer solution to a $1000 \mathrm{~mL}$ graduated cylinder and add water to bring final volume to $1000 \mathrm{~mL}$. Cover with parafilm and mix thoroughly.

9) Pore into a 1L autoclavable bottle with a screw top lid.

10) Store in refrigerator until ready to use. Agar media will solidify after heating and should thus be autoclaved just before pouring the plates. Cooling takes about 1-2 hours after removed from the autoclave.

11) Prepare tools and jars for surface sterilization, rinsing and storing. (Might need more depending on number of explants.):

a. Fill $3500 \mathrm{~mL}$ jars with de-ionized (DI) water for rinsing.

b. Place the following tools inside 2 paper bags, fold tops twice and stapled: 2 scalpel handles, scalpel blade remover and 2 forceps.

c. Place unbleached paper towels, cut in half, into foil and securely wrap. Need twice as many as the number of branch tips to be plated plus a few extras.

d. Prepare an empty $500 \mathrm{~mL}$ jar for storing buds after sterilization. 
12) Autoclave nutrient media on "sterile" for 15 minutes, then cool on slow exhaust. The autoclave should attain a temperature of $121^{\circ} \mathrm{C}$ for 15 minutes.

13) Autoclave the following supplies on "sterile" for 30 minutes. (The autoclave should attain a temperature of $121^{\circ} \mathrm{C}$ for 15 minutes.)
a. Rinsing water (3500mL jars)
b. Empty storage jar
c. Scalpel handles, forceps and blade removers
d. Paper towels wrapped in foil

\section{C) Pour plates}

1) The pouring of plates should be done when the outside of the media jar is cool enough to touch with bare hands. This takes about 1-2 hours.

2) Sterilize the laminar flow hood liberally with $70 \%$ ethanol and wipe down with unbleached towels. Start the fan. After a few minutes spray the hood down again.

3) Wipe down bag of sterilized petri plates and jar containing nutrient media with $70 \%$ ethanol and place inside the hood.

4) Cut open bag with scissors and remove 5-6 plates being careful not to contaminate the other plates by opening them. Place the plates in the center of the hood.

5) One-by-one, lift the lid and fill each plate $2 / 3$ full. Replace the lid and carefully set each plate aside to solidify. Do not move the plates until they are completely solidified.

\section{D) Explant collection}

1) Collect shoot tips with hardened buds that have not yet elongated. Clip end of branch below the needles.

2) Store the branch tips in sealed plastic bags with unbleached paper towel dampened with deionized water. Store over ice or inside the refrigerator until ready to use. This should be within 24 hours.

\section{E) Explant preparation and sterilization}

1) Prepare the branch tips by cutting to fit in a large beaker and trimming the needles. Spin in sterile water with Tween 20 for 15 minutes.

2) Remove from beaker. Strip needles and trim the shoot tip to 1 inch below the base of the bud scales. This will be used for grabbing on to with forceps during processing before plating.

3) Before beginning shoot tip sterilization, sterilize laminar flow hood liberally with $70 \%$ ethanol and wipe down with unbleached towels. Run the fan for a few minutes. Spray down again.

4) Wipe surface of 2 rinse jars and empty storage jar with $70 \%$ ethanol and place inside hood.

5) Add equal amounts of bleach and deionized water to a beaker with a few drops of Tween 20 and a stir bar. Spin for about 15 minutes.

6) Remove shoot tips from beaker using forceps and transfer to $1^{\text {st }}$ rinse jar outside hood. Cover, wipe down with ethanol and move into hood.

7) Remove shoot tips using forceps and transfer to $2^{\text {nd }}$ rinse jar. Swirl and repeat in $3^{\text {rd }}$ rinse jar. 
8) Grab shoot tips and tap on top of jar before transferring to dry sterile jar. Cover until ready to use.

\section{F) Plating explants}

1) Spray all needed supplies with $70 \%$ ethanol and place inside the hood, along the sides toward the back.. Include sterilized tools, scalpel blades, alcohol lamp, jar of 100\% ethanol, matches and sterilized paper towels inside foil. The petri plates and sterilized buds should already be inside. Be sure that the center of the hood is cleared for working and there is nothing blocking the air flow through the center.

2) Remove the first set of tools from the paper bag and place them inside the ethanol jar.

3) Light the alcohol lamp.

4) Wipe your hands down with $70 \%$ ethanol and if you have long hair, tie it back.

5) Spray and wipe center of hood with alcohol using a sterile paper towel. Place a new sterile paper towel in the center of the hood.

6) Place a fresh scalpel blade on the scalpel handle and put it in the alcohol jar. Flame the forceps and use them to remove a bud from the jar and place in on paper towel.

7) Flame the scalpel.

8) Holding the bud by the cut end with the forceps, use the scalpel to cut a shallow longitudinal line from the base of the bud scales to the tip. Starting at this line remove the scales with the point of the scalpel, being careful not to cut too damage the buds. Continue all the way around.

9) After bud scales have been removed, determine the number of pieces can be used.

a. If the shoot tip is $5-9 \mathrm{~mm}$, there is enough for 1 explant.

b. If the shoot tip is $10 \mathrm{~mm}$ or greater there is enough for 2 or more explants. Each explant should be about $5 \mathrm{~mm}$.

10) To divide the shoot tip into pieces, stick the scalpel into the shoot tip shallowly at the desired breaking point. Then bend to break the shoot tip.

11) Use the forceps to insert the bud piece into the agar. You should feel the agar give a bit. After several buds have been placed into the plate, wrap with half a square of parafilm to seal and label appropriately.

12) After plating, incubate explants in a growth chamber, programmed for 16 hours light, 8 hours dark and maintain a light temperature of $27^{\circ} \mathrm{C}$ and a dark temperature of $22^{\circ} \mathrm{C}$. Plant should be situated beneath cool white florescent bulbs situated so the light irradiance is $80 \mu \mathrm{Em}^{-2} \mathrm{~s}^{-1}$.

13) Results should be seen after 4-5 weeks.

\section{G) Transfer after 1 month}

1) After 1 month, transfer growing shoot to full LP basal salt media. Use the same media preparation and plating procedures as described above with $3.6 \mathrm{~g} / \mathrm{L} \mathrm{LP}$.

2) Individual shoots from each culture can be pulled apart and plated separately.

3) Transfer shoots every month until the desired number of shoots has been reached.

H) Rooting - Dr. Walter Mark is in the process of developing a protocol for rooting shoots from Monterey pines. 